\title{
Evidence that Cisplatin-induced Auditory Damage is Attenuated by Downregulation of Pro-inflammatory Cytokines Via Nrf2/HO-1
}

\author{
HongSeob So ${ }^{1}$, HyungJin Kim ${ }^{1,4}$, Yunha Kim ${ }^{1}$, Eunsook Kim ${ }^{1}$, Hyun-Ock Pae ${ }^{1}$, Hun-Taeg Chung ${ }^{1}$, \\ Hye-Jung Kim ${ }^{2}$, Kang-Beom Kwon ${ }^{3}$, Kang-Min Lee ${ }^{4}$, HaA-Yung Lee ${ }^{5}$, Sung-Kyun Moon ${ }^{5}$, \\ AND RAEKIL PARK ${ }^{1}$, \\ ${ }^{1}$ Vestibulocochlear Research Center E Department of Microbiology, School of Medicine, Wonkwang University School of \\ Medicine, 344-7 Shinyong-dong, Iksan, Jeonbuk 570-749, South Korea \\ ${ }^{2}$ Department of Family Medicine, Wonkwang University Hospital, Iksan, Jeonbuk 570-749, South Korea \\ ${ }^{3}$ Depeartment of Physiology, School of Oriental Medicine, Wonkwang University, Iksan, Jeonbuk 570-749, South Korea \\ ${ }^{4}$ Division of Biological Sciences, Chonbuk National University, Jeonbuk, 561-756, South Korea \\ ${ }^{5}$ Gonda Department of Cell and Molecular Biology, House Ear Institute, Los Angeles, CA 90057, USA
}

Received: 27 September 2007; Accepted: 29 April 2008; Online publication: 27 June 2008

\begin{abstract}
Recently, we demonstrated that pro-inflammatory cytokines such as TNF- $\alpha$, IL-1 $\beta$, and IL-6 played a critical role in cisplatin-induced cochlear injury and that flunarizine, known as a T-type $\mathrm{Ca}^{2+}$ channel antagonist, induced a cytoprotective effect against cisplatin cytotoxicity in HEI-OC1 cells by the activation of NF-E2related factor 2 (Nrf2)/heme oxygenase-1 (HO-1) cascade through PI3K-Akt signaling but calciumindependent pathway. We report here that flunarizine markedly attenuates cisplatin-induced pro-inflammatory cytokine secretion and their messenger RNA transcription as well as cisplatin cytotoxicity through the activation of Nrf2/HO-1 and downregulation of NF- $\kappa$ B. In HEI-OC1 cells, overexpression of Nrf2/HO1 by gene transfer or pharmacological approaches attenuated cisplatin-induced cytotoxicity and proinflammatory cytokine production. On the contrary, inhibition of Nrf2/HO-1 signaling by pharmacological inhibitors or specific small interfering RNAs signifi-
\end{abstract}

Correspondence to: Raekil Park - Vestibulocochlear Research Center \& Department of Microbiology, School of Medicine · Wonkwang University School of Medicine - 344-7 Shinyong-dong, Iksan, Jeonbuk 570-749, South Korea. Telephone: +82-63-8506777; fax: +82-63-8520220; email: rkpark@wku.ac.kr cantly abolished the beneficial effects of flunarizine. Flunarizine also attenuated cisplatin-mediated MAPK activation and pharmacological inhibition of MAPKs, especially MEK1/ERK, blocked cisplatin-induced NF$\kappa \mathrm{B}$ activation in HEI-OC1 cells. Furthermore, WT-Nrf2 overexpression effectively blocked MAPK activation after cisplatin exposure. Finally, orally administrated Sibelium ${ }^{\mathrm{TM}}$, the trade name of flunarizine, suppressed the increase of pro-inflammatory cytokines by cisplatin in both serum and cochleas of mice, whereas it increased HO-1 expression in cochleas. These results indicate that flunarizine induces a protective effect against cisplatin ototoxicity through the downregulation of NF- $\kappa$ B by Nrf2/HO-1 activation and the resulting inhibition of pro-inflammatory cytokine production in vitro and in vivo.

Keywords: cisplatin, flunarizine, inflammation, Nrf2, MAPKs, auditory cells

\section{INTRODUCTION}

Cisplatin (cis-diaminedichloroplatinum II) is an extensively used chemotherapeutic agent in the treatment of various solid tumors (Fram 1992). However, serious side effects of cisplatin, including progressive irreversible 
nephrotoxicity and ototoxicity, greatly impair the patient's quality of life and frequently results in a reduction in application dose or discontinuation of treatment. A number of studies have demonstrated the direct cytotoxic mechanisms of cisplatin including DNA damage, mitochondrial dysfunction, and the formation of reactive oxygen species (ROS; Rybak and Somani 1999). Cisplatin ototoxicity occurs primarily in the cochleae, especially in the outer hair cells (OHCs) of the organ of Corti (McAlpine and Johnstone 1990). Recently, it was reported that the inner ear has the capacity to generate an active immune response (Satoh et al. 2003), resulting in hearing loss in some individuals caused by aggravated immune responses in the inner ear (McCabe 2004). Treatment with immunosuppressive drugs, including steroids, has been shown to restore cochlear function in some patients (Kanzaki and Ouchi 1981). Yoshida et al. (1999) reported that inflammatory response mediators, including IL-6, TNF- $\alpha$, MCP-1, KC, MIP-2, sICAM-1, and VEGF, were produced from spiral ligament fibrocytes stimulated with pro-inflammatory cytokines such as IL- $1 \beta$ and TNF- $\alpha$. Consequently, inflammatory response mediators induce the infiltration of inflammatory cells, which may prolong the inflammatory response leading to fibrocyte damage and cochlear malfunction. In a previous study, we also demonstrated that pro-inflammatory cytokines play a critical role in cisplatin-induced cochlear injury (So et al. 2007). TNF- $\alpha$ plays an especially important role in this process, as the inhibition of TNF- $\alpha$ action significantly attenuated the expression of other pro-inflammatory cytokines after cisplatin injection.

We also reported that flunarizine, an antagonist of the T-type specific calcium channels, protected HEIOC1 cells from cisplatin cytotoxicity by calciumindependent mechanisms. Interestingly, flunarizine itself increased the intracellular levels in HEI-OC1 cells (So et al. 2005). Furthermore, the intracellular $\mathrm{Ca}^{2+}$ chelator BAPTA-AM and the calcium ionophore A23187 had no effect on cisplatin cytotoxicity or on the protective effect of flunarizine. These data suggest that in HEI-OC1 cells, the protective effect of flunarizine against cisplatin is mediated by calciumindependent mechanisms in HEI-OC1 cells (So et al. 2005). Furthermore, we reported that flunarizine stimulates the Nrf2-driven transcriptional activation via the antioxidant response element (ARE) through PI3K-Akt signaling and thereby increases the generation of HO-1, which plays a crucial role in protecting auditory cells from cisplatin cytotoxicity (So et al. 2006). In addition, among the catabolic metabolites of HO-1, both carbon monoxide (CO) and bilirubin are directly involved in the protective role of HO-1 against cisplatin through the inhibition of ROS generation (Kim et al. 2006). However, it has not been determined whether flunarizine protects auditory cells from cisplatin cytotoxicity through the modulation of Nrf2/HO-1 and NF- $\mathrm{BB}$ signaling in the generation of pro-inflammatory cytokines.

In the present study, we examined the effect of flunarizine and Nrf2/HO-1 on the pro-inflammatory cytokine secretion due to cisplatin in vitro using HEIOC1 cells and in vivo. Herein, we demonstrate that flunarizine induces a protective effect against cisplatin cytotoxicity through the downregulation of NF-KB by Nrf2/HO-1 activation and the resulting inhibition of pro-inflammatory cytokine production.

\section{METHODS}

\section{Reagents}

Cisplatin, flunarizine, 3-(4,5-dimethylthiazol-2-yl)-2,5diphenyl-tetrazolium bromide (MTT), hemoglobin $(\mathrm{Hb})$ were purchased from Sigma Chemical Co. (Sigma, St. Louis, MO, USA). Bilirubin, hemin, cobalt protoporphyrin IX (CoPPIX), tin protoporphyrin IX (SnPPIX), and zinc protoporphyrin IX (ZnPPIX) were obtained from Porphyrin Products (Logan, UT, USA). For CO supply into cultures, we used dimethyl sulfoxide (DMSO)-solubilized CO-RM2 ([Ru $\left.(\mathrm{CO})_{3} \mathrm{Cl}_{2}\right]_{2}$, Frontier Scientific Inc., Logan, UT, USA), which was able to release $\mathrm{CO}$ spontaneously into culture medium. The plastic culture wares were bought from Becton Dickinson and Company (Franklin Lakes, NJ, USA). Dulbecco's modified essential medium (DMEM), fetal bovine serum (FBS, Gibco BRL, Gaithersburg, MD, USA), and other tissue culture reagents were obtained from Life Technologies Inc (Gaithersburg, MD, USA). Anti-TNF- $\alpha$, anti-IL-1 $\beta$, antiIL-6, and enzyme-linked immunosorbent assay (ELISA) kits (Quantikine ${ }^{\mathrm{R}}$ ) for cytokines were purchased from R\&D Systems Inc. (Minneapolis, MN, USA). For Western blotting, anti-Lamin B, anti-NF- $\kappa$ B (p65), and anti-IkB antibodies were obtained from Santa Cruz Biotech Inc. (Santa Cruz, CA, USA). Antibodies against MAPKs were bought from Cell Signaling Inc. (Beverly, MA, USA). Pharmacological inhibitors of MAPK, including PD98059, SP600125, SB203580 and U0126, and anti-HO-1 antibody were purchased from Calbiochem (San Diego, CA, USA).

\section{Cell culture and viability}

The establishment and characterization of the conditionally immortalized HEI-OC1 cells was described in Kalinec et al. (2003). Expressions of hair-cell-specific markers, such as Prestin and Math1, were detected in HEI-OC1 cells (data not shown). HEI-OC1 cells were maintained in high glucose Dulbecco's modified Eagle medium (DMEM, Gibco BRL) containing 10\% FBS. For the experiments described below, HEI-OC1 cells 
were cultured under permissive conditions: $33^{\circ} \mathrm{C}, 7 \%$ $\mathrm{CO}_{2}$ in DMEM supplemented with $10 \%$ FBS. Cells (3× $10^{4}$ cells/each well of 24-well plate) were plated for $16 \mathrm{~h}$ and further incubated with $20 \mu \mathrm{M}$ cisplatin for $36 \mathrm{~h}$. To determine the cell viability, MTT $(0.25 \mathrm{mg})$ was added to $1 \mathrm{ml}$ of cell suspension for $4 \mathrm{~h}$. After three washes of cells with phosphate-buffered saline (PBS, $\mathrm{pH}$ 7.4), the insoluble formazan product was dissolved in DMSO. Then, the optical density (O.D.) of each culture well was measured using Microplate reader (Titertek Multiskan, Flow Laboratories) at $590 \mathrm{~nm}$. The O.D. in control cells was taken as $100 \%$ of viability.

\section{Measurement of pro-inflammatory cytokines by ELISA}

To measure the secretion of pro-inflammatory cytokines from cisplatin-treated HEI-OC1 cells, cells $(3 \times$ $10^{4}$ cells/each well of 24-well plate) were plated for $16 \mathrm{~h}$ and further incubated with $20 \mu \mathrm{M}$ cisplatin for $24 \mathrm{~h}$ in the presence of various doses of flunarizine. Then, culture supernatants were harvested at each time point, and the levels of secreted pro-inflammatory cytokines were determined by ELISA (Quantikine Cytokine Kits; R\&D Systems Inc.) according to the manufacturer's instructions. Briefly, $50 \mu \mathrm{l}$ of standard cytokine (serially diluted from $1,500 \mathrm{pg} / \mathrm{ml}$ to $23.4 \mathrm{pg} / \mathrm{ml}$ ) or culture supernatant was added to each well and incubated for $2 \mathrm{~h}$ at room temperature. Each well was washed two times with wash buffer and then further incubated for $30 \mathrm{~min}$ with $100 \mu \mathrm{l}$ of substrate solution. The optical density of each well was determined using a microplate reader at $450 \mathrm{~nm}$. A standard curve for each cytokine was generated. On the basis of this standard curve, linear regression analysis was performed using Microcal Origin 6.0 software (Northampton, MA, USA). The equation from the line of best fit for the standards was used to determine supernatant cytokine concentration. This standard curve was reset at every experiment.

\section{Transfection of Nrf2, HO-1, and siRNAs} constructs into HEI-OC1 cells

Wild-type Nrf2 (WT-Nrf2) and dominant-negative mutant of Nrf2 (DN-Nrf2) were generated by polymerase chain reaction (PCR) amplification of mouse complementary DNA (cDNA) with oligonucleotide pairs KpnINrf2: 5'-CGG GGT ACC ATG GAT TTG ATT GAC ATC C-3' and XbaINrf2: 5'-TGC TCT AGA CTA

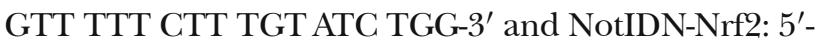
GCA CGC GGC CGC CAT GGG TGA ATC CCA ATG TGA A-3' and XbalNrf2: 5'-TGC TCT AGA CTA GTT TTT CTT TGT ATC TG-3', respectively, as described previously (So et al. 2006). For transient transfections, cells were plated on 60 -mm dishes $\left(5 \times 10^{5}\right.$ cells $/ 60$-mm dish) 1 day before transfection. A DNA solution containing $1 \mu \mathrm{g}$ of the each plasmid (pCDNA3.1, pcDNA3.1 containing WT-Nrf2 or DN-Nrf2), $5 \mu \mathrm{l}$ of the FuGENE6 transfection reagent (Roche, Boehringer Mannheim, Germany), and $95 \mu \mathrm{l}$ of a serumfree medium was added to the cultured cells. After $48 \mathrm{~h}$ incubation, each transfectant were confirmed by Western blot analysis. Inhibition of Nrf2 and HO-1 expression was also assessed by Western blotting analysis after transfection of HEI-OC1 cells with Nrf2 and HO-1 small interfering RNA (siRNA), respectively. The Nrf2 siRNAs construct is a pool of three sequences of siRNA as follows; 1170 forward: 5'-CUC UGA CUC UGG CAU UUC Att-3', 1170 reverse: 5'-UGA AAU GCC AGA GUC AGA Gtt-3', 1402 forward: 5'-CGU GAA UCC CAA UGU GAA Att-3', 1402 reverse: 5'UUU CAC AUU GGG AUU CAC GTT-3', 1826 forward: 5'-CCU UGU AUC UUG AAG UCU Utt-3', 1826 reverse: 5'-AAG ACU UCA AGA UAC AAG Gtt-3'. The HO-1 siRNAs are also a pool of three sequences of siRNA as follows; 282 forward: 5'-GCU UCC UUG UAC CAU AUC Utt-3', 282 reverse: 5'-AGA UAU GGU ACA AGG AAG Ctt-3', 745 forward: 5'-CCU UCC UGC UCA ACA UUG Att, 745 reverse: 5'-UCA AUG UUG AGC AGG AAG Gtt-3', 1,525 forward: 5'-CUC UAA CUU CUG UGU GAA Att-3', 1,525 reverse: 5'-UUU CAC ACA GAA GUU AGA Gtt-3'. All siRNA constructs were purchased from Santa Cruz Biotechnology. Briefly, cells were grown in 24-well plates and transiently transfected with $0.5 \mu \mathrm{g}$ of Nrf2, HO-1, or control siRNA constructs mixed with X-tremeGENE siRNA transfection reagent (Roche Applied Science, Penzberg, Germany) according to the manufacturer's protocol. After incubation at $33^{\circ} \mathrm{C}$ and $5 \% \mathrm{CO}_{2}$ for $36 \mathrm{~h}$, cells were further treated with cisplatin and flunarizine. Samples were then prepared and analyzed for viability or reverse transcriptase (RT)-PCR.

\section{Preparation of cytosolic and nuclear extracts}

Cells were washed with ice-cold PBS, scraped, and centrifuged at $1,000 \times \mathrm{g}$ for $5 \mathrm{~min}$ at $4^{\circ} \mathrm{C}$. The cell pellet was resuspended in $200 \mu \mathrm{l}$ of lysis buffer (10 mM HEPES, pH 7.9, $1.5 \mathrm{mM} \mathrm{MgCl}_{2}, 10 \mathrm{mM} \mathrm{KCl}$, $0.5 \mathrm{mM}$ phenylmethylsulfonyl fluoride, and $0.5 \mathrm{mM}$ dithiothreitol) and incubated on ice for $15 \mathrm{~min}$. At the end of this incubation, $10 \mu \mathrm{l}$ of $10 \%$ NP-40 was added, and the tube was vortexed for $10 \mathrm{~s}$. After centrifugation at $13,000 \times \mathrm{g}$ for $1 \mathrm{~min}$ at $4^{\circ} \mathrm{C}$, supernatant (cytosolic extract) was collected and stored at $-80^{\circ} \mathrm{C}$, whereas the pellet was further processed to obtain nuclear extracts. The pellet was resuspended in extraction buffer (5 mM HEPES, pH 7.9, $1.5 \mathrm{mM}$ $\mathrm{MgCl}_{2}, 0.5 \mathrm{mM}$ phenylmethylsulfonyl fluoride, $0.2 \mathrm{mM}$ ethylenediaminetetraacetic acid (EDTA), $0.5 \mathrm{mM}$ dithiothreitol, and glycerol $25 \% \mathrm{vol} / \mathrm{vol}$ ) 
and incubated for $30 \mathrm{~min}$ at $4^{\circ} \mathrm{C}$. Nuclear extract was isolated by centrifugation at $13,000 \times g$ for $30 \mathrm{~min}$ at $4^{\circ} \mathrm{C}$. The supernatant was aliquoted and stored at $-80^{\circ} \mathrm{C}$ until used for Western blot analysis. Protein concentration was determined by the Lowry method.

\section{Western blot analysis}

Western blot analysis was performed as follows. Briefly, cells were harvested and washed twice with ice-cold PBS. Whole and nuclear/cytosolic fractionated lysates were subjected to electrophoresis on $12 \%$ sodium dodecyl sulfate (SDS)-polyacrylamide gels for $3 \mathrm{~h}$ at $20 \mathrm{~mA}$ and then transferred onto nitrocellulose. The membrane was incubated in 5\% (wt/vol) dried milk protein in PBS containing $0.05 \%$ (vol/vol) Tween-20 (PBS-T) for $1 \mathrm{~h}$, washed in PBS-T, and then further reacted with primary antibody $(1: 1,000)$ for $1 \mathrm{~h}$. The membrane was extensively washed with PBS-T and then incubated with anti-rabbit IgG antibody conjugated to HRP $(1: 3,000)$ for $1 \mathrm{~h}$. After extensive washes, protein bands on the membrane were visualized using chemiluminescent reagents according to the manufacturer's instructions (Supersignal Substrate; Pierce, Rockford, IL, USA).

\section{In vivo experiment of cisplatin ototoxicity}

Twenty-seven male Balb/c mice, weighing between 20 and $23 \mathrm{~g}$ at 7 weeks, were used in this study. The animals were fed a standard commercial diet, housed in a room at $20-22^{\circ} \mathrm{C}$ ambient temperature with a relative humidity of $50 \pm 5 \%$ and 12:12 $\mathrm{h}$ of light and dark cycle. The animals were randomly divided into three groups (group 1, control, $n=8$; group 2, cisplatin, $n=13$; group 3 , cisplatin plus Sibelium, $n=6$ ). Group 1 animals received intraperitoneal injection of PBS. Group 2 animals were intraperitoneally administered with cisplatin only ( $4 \mathrm{mg} / \mathrm{kg}$, body weight) for 4 days. Group 3 animals were orally received Sibelium $(143 \mu \mathrm{g} / \mathrm{kg}$, body weight) at $12 \mathrm{~h}$ before and at the same time as cisplatin injection for four consecutive days. The animals in all groups were killed under anesthesia on the next day after final cisplatin injection, and the whole temporal bone was removed. Before killing, blood was collected into commercial tubes containing EDTA. The serum was stored at $-30^{\circ} \mathrm{C}$ until analysis for cytokine measurements. The experimental protocol was approved by the Animal Care and Use Committee at the Wonkwang University School of Medicine.

\section{Immunohistochemical studies and TUNEL assay}

The removed temporal bone was fixed in $4 \%$ paraformaldehyde for $16 \mathrm{~h}$, decalcified with 10\% EDTA in PBS for 2 weeks, dehydrated, and embedded in paraffin wax. Sections of $5 \mu \mathrm{m}$ were deparaffinized in xylene and rehydrated through graded concentrations of ethanol. For immunohistochemical study, the kit (DAKO LSAB Universal K680, Carpinteria, CA, USA) was used and all the procedures were carried out according to the manufacturer's instruction. The endogenous peroxidase was blocked with 3\% hydrogen peroxide for $5 \mathrm{~min}$ at room temperature. After sections were washed in PBS, nonspecific binding was blocked with $1 \%$ bovine serum albumin for $1 \mathrm{~h}$. Then, primary antibody (1:200 diluted) was added to the slides, and incubation proceeded for $1 \mathrm{~h}$. After repeated washes with PBS, the section was incubated with biotinylated secondary antibody for $1 \mathrm{~h}$ and then covered for $15 \mathrm{~min}$ with streptavidin peroxidase. Finally, after repeated washes with PBS, the section was stained in a freshly prepared substrate solution (3 $\mathrm{mg}$ of 3-amino-9-ethylcarbazole in $10 \mathrm{ml}$ of sodium acetate buffer $\mathrm{pH} 4.9,500 \mu \mathrm{l}$ of dimethylformamide, $0.03 \%$ hydrogen peroxide) for $10 \mathrm{~min}$. The nuclei of immunostained cells were counterstained with Mayer's hematoxylin (Sigma-Aldrich Co.). The following primary antibodies were employed: anti-TNF- $\alpha$ (goat polyclonal anti-mouse TNF- $\alpha$, R\&D Systems); anti-IL$1 \beta$ (goat polyclonal anti-mouse IL-1 $\beta, R \& D$ Systems \#AF-401-NA); anti-IL-6 (goat polyclonal anti-mouse IL6, R\&D Systems); and anti-NF-אB p65 (rabbit polyclonal IgG, Santa Cruz). The active and cleaved form of IL-1 $\beta$ could not be detected in cytoplasm because of its fast secretion. Therefore, to detect IL- $1 \beta$, we used antiIL-1 $\beta$ recognizing inactive form of IL-1 $\beta$.

Apoptotic cells were detected in situ utilizing the terminal deoxynucleotidyl transferase (TdT)-mediated dUTP nick end-labeling (TUNEL) assay (TUNEL POD kit, Roche Molec Biochemic, Mannheim, Germany). Briefly, a section was deparaffinized and rehydrated. After incubation with $20 \mu \mathrm{g} / \mathrm{ml}$ proteinase $\mathrm{K}$ (Boehringer Mannheim), the blocking of endogenous peroxidase was carried out using $2 \% \mathrm{H}_{2} \mathrm{O}_{2}$ in methanol for $30 \mathrm{~min}$ at room temperature. Then tissue section was washed in PBS and incubated with labeling solution for $1 \mathrm{~h}$ at $37^{\circ} \mathrm{C}$. After washing, the section was incubated with converter-POD for $30 \mathrm{~min}$. DAB was used as a substrate. The nuclei of immunostained cells were counterstained with Mayer's hematoxylin (Sigma-Aldrich Co.).

\section{Reverse transcriptase PCR and quantitative real-time PCR amplification}

Total RNA was extracted from whole cochlea of left ear of rat with the use of TRIzol (Invitrogen) according to the manufacturer's protocol. Single-stranded cDNA was synthesized from total RNA. Then, PCR with Taq DNA polymerase (Takara, Takara Shuzo, Japan) was performed for 30 cycles using the following protocol: $95^{\circ} \mathrm{C}$ for $40 \mathrm{~s}, 58^{\circ} \mathrm{C}$ for $40 \mathrm{~s}$, and $72^{\circ} \mathrm{C}$ for $50 \mathrm{~s}$. Then, $10 \mu \mathrm{l}$ of 
the PCR products was separated on $1.2 \%$ agarose gel and visualized under UV. The sequences of primers used for PCR amplification are as follows: $\beta$-actin (forward, 5'-GAA GAG CTA TGA GCT GCC TGA-3' and reverse, $5^{\prime}$-TGA TCC ACA TCT GCT GGA AGG-3'); TNF- $\alpha$ (forward, $5^{\prime}$-CAG GGG CCA CCA CGC TCT TC$3^{\prime}$ and reverse, $5^{\prime}$-CTT GGG GCA GGG GCT CTT GAC3'); IL-1 $\beta$ (forward, 5'-AAG GAG ACC AAG CAA CGA C-3', and reverse, $5^{\prime}$-GAG ATT GAG CTG TCT GCT CA3'); IL-6 (forward, 5'-TTG CCT TCT TGG GAC TGA TGC-3' ${ }^{\prime}$ and reverse, $5^{\prime}$-TTG GAA ATT GGG GTA GGA AGG A-3') ; and HO-1 (forward, 5'-CTC ACA GAT GGC GTC ACT TCG TCA-3' ${ }^{\prime}$ and reverse, $5^{\prime}$-GGA TTT GGG GCT GCT GGT TTC A-3' ${ }^{\prime}$ ). Real-time PCR analysis using TaqMan fluorescence methods was performed for quantitative analysis of messenger RNAs (mRNAs). The products were amplified using LightCycler II PCR machine (Roche Diagnostics, Basel, Switzerland) in the reaction mixture (20 $\mu \mathrm{l}$ ) containing $2 \mu \mathrm{l}$ of LightCyclerFastStart DNA Master Taqman (Roche), $0.5 \mu \mathrm{mol} / \mathrm{l}$ each primer, and $3 \mathrm{mmol} / 1 \mathrm{MgCl}_{2}$. The forward, reverse, and probe oligonucleotide primers for multiplex realtime TaqMan PCR are as follows: for mouse TNF- $\alpha$ (forward, 5'-TCT CTT CAA GGG ACA AGG CTG-3'; reverse, 5'-ATA GCA AAT CGG CTG ACG GT-3'; probe, 5'-CCC GAC TAC GTG CTC CTC ACC CA$3^{\prime}$ ), for mouse IL-1 $\beta$ (forward, $5^{\prime}$-TTG ACG GAC CCC AAA AGA T-3'; reverse, 5'-GAA GCT GGA TGC TCT CAT CTG-3'; universal probe, M15131.1-Roche Applied Science), for mouse IL-6 (forward, 5'-TTC ATT CTC TTT GCT CTT GAA TTA GA-3'; reverse, 5'-GTC TGA CCT TTA GCT TCA AAT CCT-3'; universal probe, M20572.1-Roche Applied Science). By using LightCycler Relative Quantification Software (Version 4.0, Roche), the amount of target gene expressions were calculated as a ratio of a target transcript relatively to $\beta$-actin (a housekeeping gene) in the same sample.

\section{Statistical analysis}

Each experiment was performed at least three times, and all values are represented as means \pm S.D of three or indicated observations in figure legends. One-way analysis of variance (ANOVA) or post hoc test for different interaction within one test was used to analyze a statistical significance of the results. Values of $p<0.05$ were considered as statistically significant.

\section{RESULTS}

Effect of flunarizine on pro-inflammatory cytokine secretion and mRNA expression in vitro

in cisplatin-treated HEI-OC1 cells

In a previous study, we demonstrated that cisplatin induces the apoptotic death of HEI-OC1 cells as shown by nuclear condensation, DNA laddering, and caspase-3 activation (So et al. 2005). However, pretreatment with flunarizine completely abolished the characteristic apoptotic features caused by cisplatin. In the present study, we measured the viability of HEIOC1 cells by MTT assay after treatment with $20 \mu \mathrm{M}$ cisplatin for $36 \mathrm{~h}$ in the presence of various doses of flunarizine. As shown in Figure 1A, flunarizine significantly inhibited cisplatin cytotoxicity in a dosedependent manner. We next investigated the effect of flunarizine on the production of pro-inflammatory cytokines in HEI-OC1 cells due to cisplatin. Culture supernatants of HEI-OC1 cells were harvested at $24 \mathrm{~h}$ after exposure to $20 \mu \mathrm{M}$ cisplatin in the presence of various doses of flunarizine. The secretion of TNF- $\alpha$, IL-1 $\beta$, and IL- 6 was determined by ELISA. As shown in Figure 1B-D, cisplatin treatment resulted in a marked increase of pro-inflammatory cytokine secretion, specifically TNF- $\alpha$, IL- $1 \beta$, and IL-6. However, the in-
A)

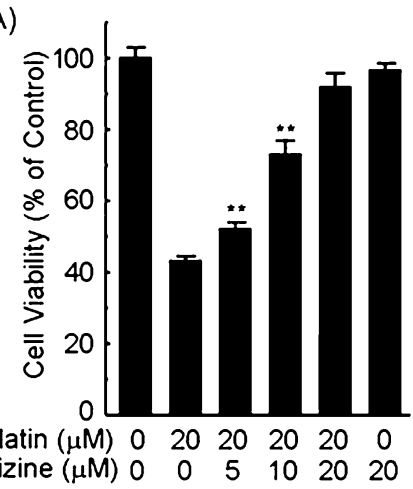

B)

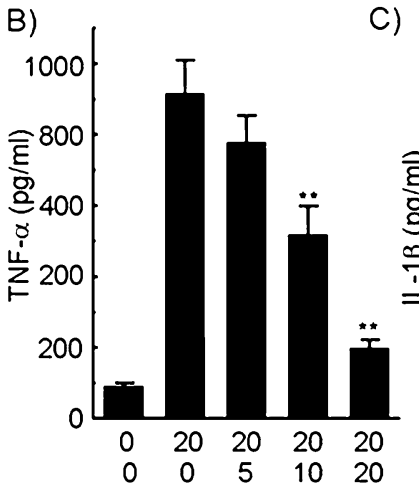

C)

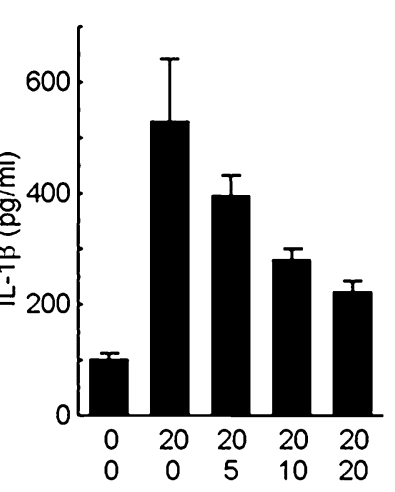

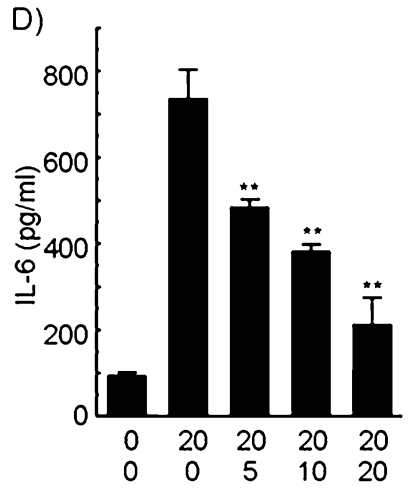

FIG. 1. Effect of flunarizine on the cisplatin-induced secretion of pro-inflammatory cytokines in $\mathrm{HEI}-\mathrm{OC} 1$ cells. Cells were treated with $20 \mu \mathrm{M}$ cisplatin in the absence or presence of flunarizine for $36 \mathrm{~h}$ (A; to measure cell viability) or $24 \mathrm{~h}$ (B-D; to measure cytokine secretion). Pro-inflammatory cytokines from culture supernatants were measured by ELISA. The data represent the mean $\pm \mathrm{SD}$ of three samples. ${ }^{*} p<0.05,{ }^{* *} p<0.01$ by one-way ANOVA. B Release of TNF$\alpha$; C Release of IL-1 $\beta$; D Release of IL-6. 
A)

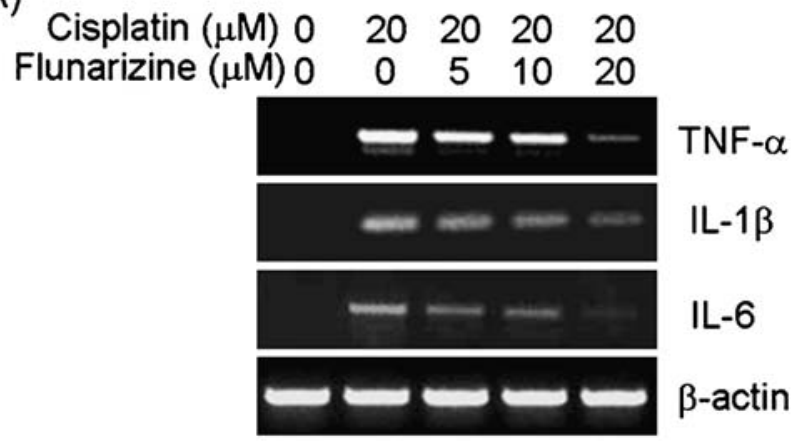

B)

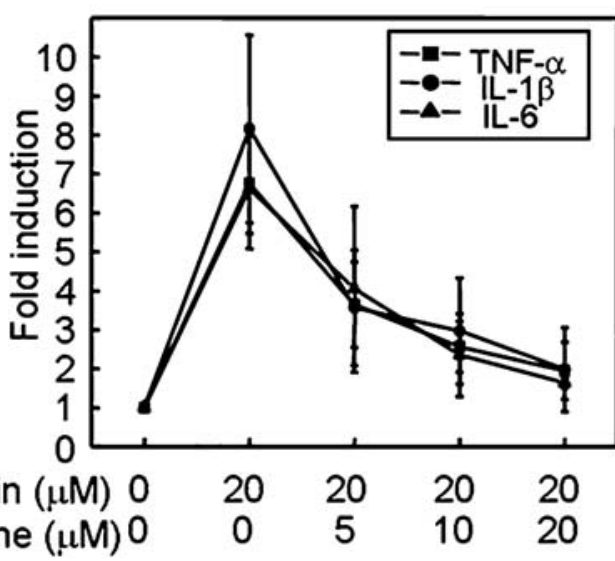

FIG. 2. Effect of flunarizine on the mRNA levels of cisplatininduced pro-inflammatory cytokines in HEI-OC1 cells. Cells were treated with $20 \mu \mathrm{M}$ cisplatin in the absence or presence of flunarizine for $24 \mathrm{~h}$. Total RNA was then isolated by TRIzol and CDNA was synthesized by reverse transcription. TNF- $\alpha$, IL-1 $\beta$, IL- 6 , and $\beta$-actin CDNAs were amplified by RT-PCR (A) or quantitative real-time PCR (B) using specific primer sets, respectively.

creased secretion of these pro-inflammatory cytokines was significantly attenuated by flunarizine in a dose-dependent manner. Next, we examined the effect of flunarizine on the levels of transcription of pro-inflammatory cytokines in cisplatin-treated HEIOC1 cells. Cisplatin clearly increased the transcriptional levels of these pro-inflammatory cytokines. However, consistent with the inhibitory effect of flunarizine on cisplatin-induced pro-inflammatory cytokine secretion, flunarizine also significantly attenuated the transcriptional levels of these proinflammatory cytokines in a dose-dependent manner (Fig. 2A and B).

\section{Ectopic expression of WT-Nrf2 attenuates} cisplatin-mediated pro-inflammatory cytokine secretion in vitro

In a previous study, we also showed that the cytoprotective mechanism of flunarizine in cisplatin cytotoxicity was mediated by the activation of Nrf2/HO-1 through PI3K-Akt signaling (So et al. 2006). Therefore, to elucidate the functional role of $\mathrm{Nrf} 2$ on pro-inflammmatory cytokine secretion, the Nrf2 expression vectors WT-Nrf2 and DN-Nrf2 were transiently introduced into HEI-OC1 cells. Transfection of WT-Nrf2 alone attenuated the cisplatin-induced secretion of TNF- $\alpha$, IL-1 $\beta$, and IL-6 (Fig. 3A-C). However, ectopic expression of DN-Nrf2 caused slight increases of cisplatin-induced TNF- $\alpha$ (not significant) and IL-1 $\beta$ $(p<0.05)$. These data indicate that $\mathrm{Nrf2}$ may provide one aspect of protection in HEI-OC1 cells from cisplatin cytotoxicity by modulating pro-inflammatory cytokine secretion.

To further assess the potential role of $\mathrm{HO}-1$ in cisplatin-induced pro-inflammatory cytokine secretion, HEI-OC1 cells were pretreated with the HO-1 inducers (Akamatsu et al. 2004), CoPPIX and hemin, for $12 \mathrm{~h}$ and further maintained in the presence of $20 \mu \mathrm{M}$ cisplatin for $24 \mathrm{~h}$. As shown in Figure 4A-C, pretreatment with hemin and CoPPIX significantly

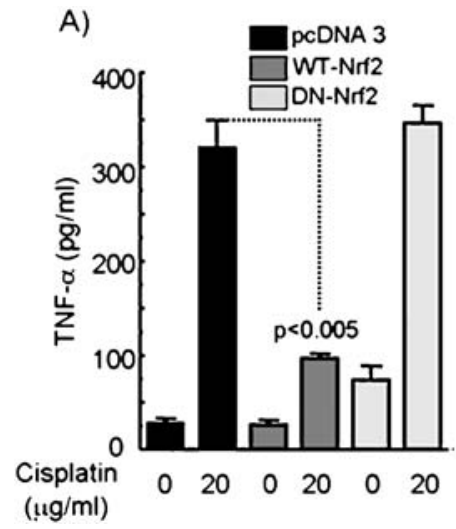

FIG. 3. Effect of Nrf2 overexpression on the cisplatin-induced secretion of pro-inflammatory cytokines in HEI-OC1 cells. Cells were transfected with Nrf2 expression vectors as described in the "Methods". After $48 \mathrm{~h}$, cells were further incubated with $20 \mu \mathrm{M}$
C)

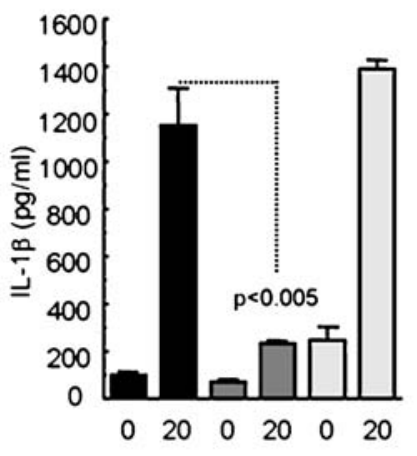

cisplatin for $24 \mathrm{~h}$. Pro-inflammatory cytokines from culture supernatants were measured by ELISA. The data represent the mean \pm SD of three samples. A Release of TNF- $\alpha$; B Release of IL-1 $\beta$; C Release of IL-6. 
A)

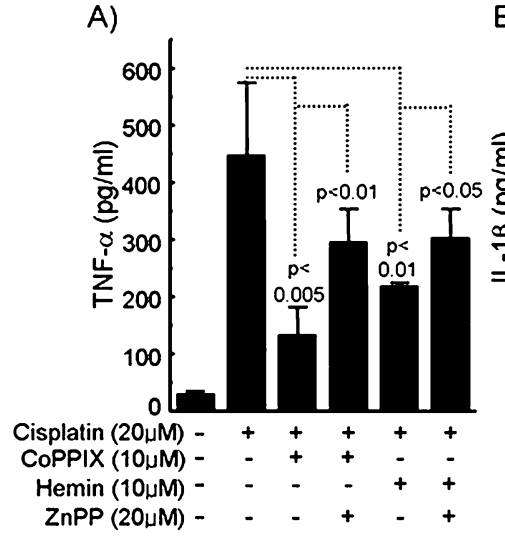

B)

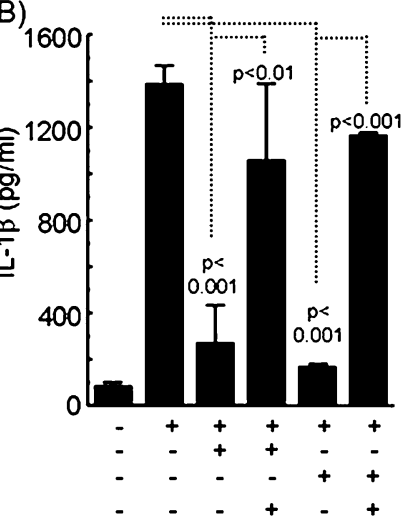

C)

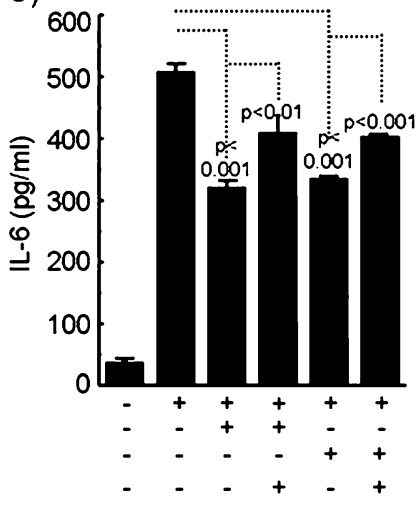

D)

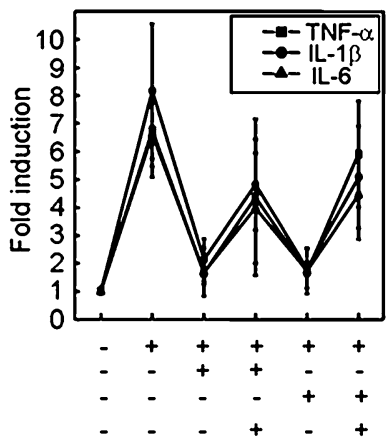

FIG. 4. Effect of pharmacological HO-1 induction on the cisplatininduced secretion of pro-inflammatory cytokines in HEI-OC1 cells. Cells were pretreated with $10 \mu \mathrm{M}$ of HO-1 inducers (CoPPIX and hemin) in the presence or absence of $20 \mu \mathrm{M}$ of ZnPPIX for $6 \mathrm{~h}$ and further incubated with $20 \mu \mathrm{M}$ cisplatin for $24 \mathrm{~h}$. Pro-inflammatory cytokines from culture supernatants were measured by ELISA. The data represent the mean \pm SD of three samples. A Release of TNF- $\alpha$; $\mathbf{B}$ Release of IL-1 $\beta$; C Release of IL-6. Total RNA was isolated by TRIzol and CDNA was synthesized by reverse transcription. TNF- $\alpha, \mathrm{IL}-1 \beta$, IL-6, and $\beta$-actin cDNAs were amplified by quantitative real-time PCR using specific primer sets (D).

The enzymatic activation of $\mathrm{HO}-1$ is required for the attenuation of pro-inflammatory cytokine secretion by flunarizine in cisplatin-treated HEI-OC1 cells

To define the role of HO- 1 for the attenuation of proinflammatory cytokine secretions by flunarizine in cisplatin-treated HEI-OC1 cells, cells were also pretreated with SnPPIX to suppress HO-1 activity in the presence of cisplatin and flunarizine (Fig. 5). As shown in Figure 5A-C, pretreatment with SnPPIX significantly alleviated the attenuation effect of flunarizine on pro-inflammatory cytokine production induced by cisplatin. SnPPIX also abolished the
A)

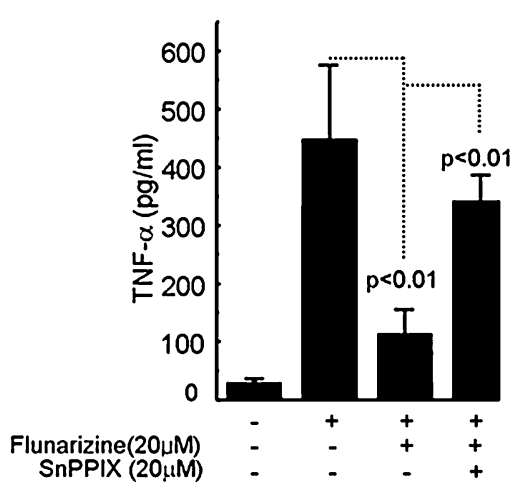

B)

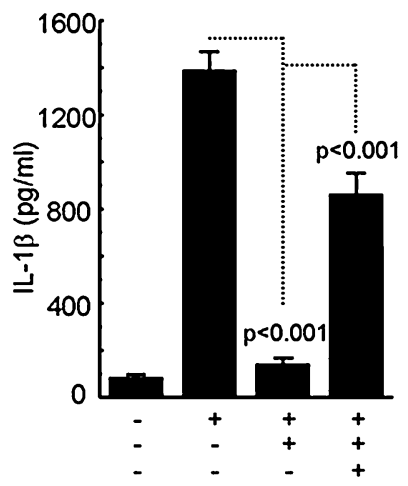

C)

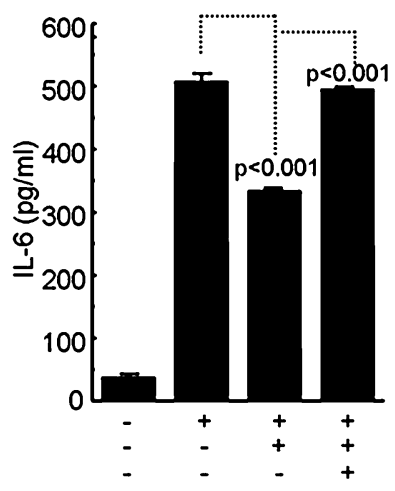

D)

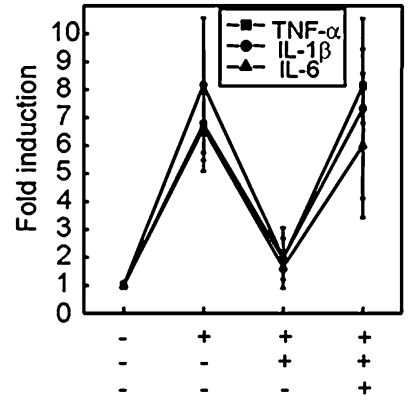

FIG. 5. Effect of pharmacological HO-1 inhibition on the attenuating effect of flunarizine against the cisplatin-induced secretion of pro-inflammatory cytokines in HEI-OC1 cells. Cells were treated with media, $20 \mu \mathrm{M}$ cisplatin, $20 \mu \mathrm{M}$ flunarizine plus cisplatin, or a combination of cisplatin, flunarizine, and $20 \mu \mathrm{M}$ SnPPIX for $6 \mathrm{~h}$. Proinflammatory cytokines from culture supernatants were measured by
ELISA. The data represent the mean \pm SD of three samples. A Release of TNF- $\alpha$; B Release of IL-1 $\beta$; C Release of IL-6. Total RNA was isolated by TRIzol and cDNA was synthesized by reverse transcription. TNF- $\alpha$, IL-1 $\beta$, IL-6, and $\beta$-actin cDNAs were amplified by quantitative real-time PCR using specific primer sets (D). 
A)

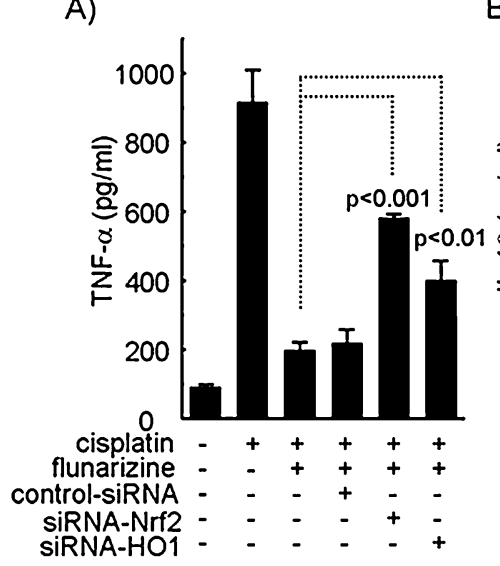

B)

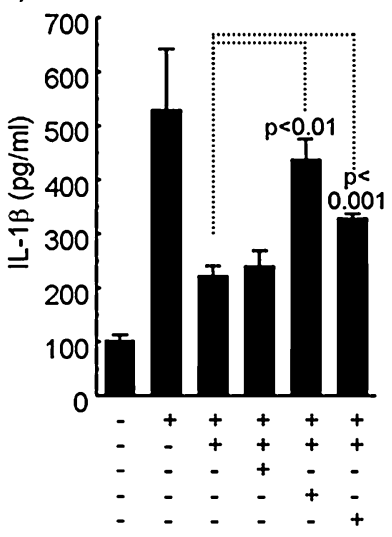

C)

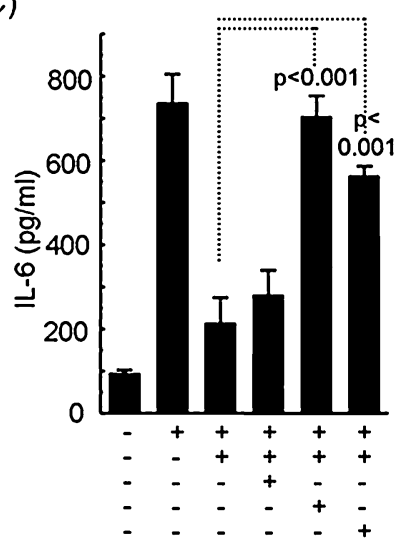

FIG. 6. Effect of Nrf2 or HO-1 knock down via siRNA transfection on the cisplatin-induced secretion of pro-inflammatory cytokines in $\mathrm{HEI}-\mathrm{OC} 1$ cells. Cells were transfected with $0.5 \mu \mathrm{g}$ siRNA constructs of Nrf2, HO-1 and control plasmid and further treated with $20 \mu \mathrm{M}$

decrease in transcriptional levels of pro-inflammatory cytokines by flunarizine in cisplatin-treated HEI-OC1 cells (Fig. 5D). To confirm that the attenuation of proinflammatory cytokine secretion by flunarizine in cisplatin-treated HEI-OC1 cells is indeed mediated through Nrf2/HO-1 activation, siRNA constructs targeting Nrf2 and HO-1 were transfected in HEI-OC1 cells. Knock down of the transcriptional expression of Nrf2 and HO-1 using these specific siRNAs was confirmed by RT-PCR as previously described (So et al. 2006). Transfection of either Nrf2 or HO-1 siRNAs, but not unrelated control siRNAs, resulted in the attenuation of flunarizine's inhibitory effect on pro-inflammatory cytokine secretion due to cisplatin (Fig. 6A-C) as well as the protective effect against cisplatin cytotoxicity (data not shown). These data indicate that the activation of both $\mathrm{Nrf2}$ and HO-1 signaling is required for the attenuation of cisplatin-induced pro-inflammatory cytokine secretion by flunarizine.

To further examine the mechanism by which end metabolites of heme catabolism by HO-1, including bilirubin, iron, and carbon monoxide $(\mathrm{CO})$, contrib- cisplatin and $20 \mu \mathrm{M}$ flunarizine for $24 \mathrm{~h}$. Pro-inflammatory cytokines from culture supernatants were measured by ELISA. The data represent the mean \pm SD of three samples. A Release of TNF- $\alpha$; B Release of IL-1 $\beta$; C Release of IL-6.

ute to the attenuation of cisplatin-mediated proinflammatory cytokine secretion in HEI-OC1 cells, cells were incubated with the CO-releasing agent CORM2, bilirubin, and ferric citrate before the addition of cisplatin (Table 1). The results show that pretreatment with CO-RM2 and bilirubin causes a significant decrease in cisplatin-induced pro-inflammatory cytokine secretion. In contrast, treatment with ferric citrate, an iron donor, could not significantly attenuate cisplatin-induced TNF- $\alpha$ secretion, whereas it induced a slight but significant attenuation of IL-1 $\beta$ and IL-6 secretion. We further examined the possibility that endogenous $\mathrm{CO}$ production by flunarizinemediated Nrf2/HO-1 activation may also account for the attenuation of cisplatin-induced pro-inflammatory cytokine secretion by flunarizine. As shown in Figure $7 \mathrm{~A}$ and $\mathrm{B}$, the addition of $\mathrm{CO}$ scavenger, hemoglobin, slightly but significantly inhibited the attenuating effect of flunarizine on TNF- $\alpha$ and IL-1 $\beta$ secretion $(p<0.01$ and $p<0.01$, respectively), indicating that flunarizine contributes to protection of cells from cisplatin through, in part, a CO-dependent attenuation of the secretion of pro-inflammatory cytokines.

TABLE 1

Cytokine secretion profiles in cisplatin-treated HEI-OC1 cells in the presence of various HO-1 enzymatic products (pg/ml)

\begin{tabular}{lccc}
\hline \multirow{2}{*}{ Exp. Group } & \multicolumn{3}{c}{ Cytokines } \\
\cline { 2 - 4 } \multicolumn{1}{c}{ Control } & $T N F-\alpha$ & $I L-1 \beta$ & IL-6 \\
Cisplatin & $88.0 \pm 10.0$ & $100.7 \pm 11.7$ & $92.1 \pm 3.0$ \\
CO-RM + cisplatin & $913.3 \pm 95.9$ & $528.2 \pm 113.5$ & $734.7 \pm 68.9$ \\
Bilirubin + cisplatin & $351.9 \pm 91.0^{* *}$ & $198.5 \pm 10.1^{* *}$ & $351.6 \pm 23.9^{* *}$ \\
FC + cisplatin & $459.7 \pm 36.7^{* *}$ & $194.8 \pm 12.0^{* *}$ & $350.0 \pm 52.1^{* *}$ \\
\hline
\end{tabular}

${ }^{*} p<0.01$ vs. cisplatin; ${ }^{* *} p<0.001$ vs. cisplatin 

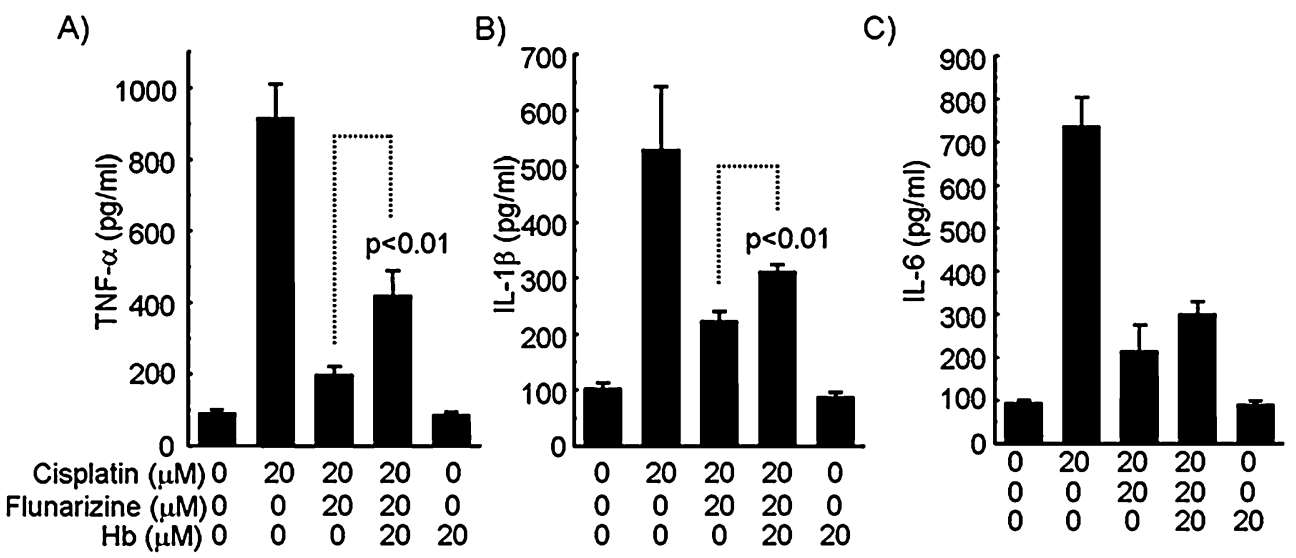

FIG. 7. Endogenous CO production in flunarizine-treated HEI-OC1 cells and its role on the attenuation of cisplatin-mediated proinflammatory cytokine secretions. To examine $\mathrm{CO}$ production in flunarizine-treated $\mathrm{HEI}-\mathrm{OC} 1$ cells and its role on the attenuation of cisplatin-mediated pro-inflammatory cytokine secretions, cells were pretreated with $20 \mu \mathrm{M}$ flunarizine in the presence or absence of
$20 \mu \mathrm{g} / \mathrm{ml}$ hemoglobin $(H b)$, a CO scavenger, and then further incubated for $24 \mathrm{~h}$ with $20 \mu \mathrm{M}$ of cisplatin. Pro-inflammatory cytokines from culture supernatants were measured by ELISA. The data represent the mean \pm SD of three samples. A Release of TNF- $\alpha$; $\mathbf{B}$ Release of IL-1 $\beta$; C Release of IL-6.
Effect of flunarizine on the nuclear translocation of NF- $\mathrm{KB}$ induced by cisplatin in HEI-OC1 cells

The transcription factor NF- $\mathrm{B}$ is involved in regulating the expression of pro-inflammatory cytokines and other pro-inflammatory mediators that participate in acute inflammatory responses (Abraham 2003). In a previous study, we demonstrated that cisplatin induces the nuclear translocation of NF- $\kappa \mathrm{B}$, and the secretion of pro-inflammatory cytokines at early time points is directly involved with NF- $\mathrm{B}$ B activation in cisplatintreated cells (So et al. 2007). However, it is not yet known whether flunarizine attenuates pro-inflammatory cytokine secretion through the modulation of NF$\mathrm{\kappa B}$ signaling. Therefore, cells were treated with cisplatin in the absence or presence of flunarizine for $1 \mathrm{~h}$ and fractionated into the nuclear and cytosolic portions for western blotting. We analyzed Lamin B expression to verify the purity of nuclear extract and equal amount loading in Western blotting analysis. Consistent with our previous results, nuclear translocation of NF-KB was observed after $1 \mathrm{~h}$ of cisplatin treatment, whereas cytoplasmic NF- $\kappa \mathrm{B}$ and $\mathrm{I} \kappa \mathrm{B}$ decreased after cisplatin exposure (Fig. 8A). However, pretreatment with flunarizine clearly attenuated the nuclear translocation of NF- $\kappa \mathrm{B}$ in a dose-dependent manner. We next investigated whether Nrf2, which is activated by flunarizine in HEI-OC1 cells, is directly involved in the downregulation of cisplatin-induced NF- $\kappa$ B activation. Transient Nrf2 overexpression were accomplished with the pcDNA3.1 WT-Nrf2 and DNNrf2 vectors, after which the cells were treated with cisplatin for $1 \mathrm{~h}$ and the nuclear translocation of NF$\kappa \mathrm{B}$ assessed. As shown in Figure 8B, WT-Nrf2 abolished both cytosolic I $\kappa \mathrm{B}-\alpha$ degradation and nuclear translocation of NF- $\mathrm{B}$ after cisplatin exposure, whereas DN-Nrf2 had no effect. These results suggest that Nrf2 activation is directly involved in the downregulation of NF- $k \mathrm{~B}$ activation by cisplatin.

In a previous report, we demonstrated that cisplatin induced the activations of the MAPKs ERK, JNK, and p38, whereas only the pharmacologic inhibition of MEK1/ERK activity rescued HEI-OC1 cells from cisplatin cytotoxicity (So et al. 2007). Thus, we examined the effect of flunarizine on cisplatin-mediated MAPKs activation. As shown in Figure 8C, flunarizine also attenuated the activation of all three types of MAPK due to cisplatin in a dose-dependent manner. Therefore, we next examined the link between NF- $\kappa \mathrm{B}$ activation and MAPK activation in cisplatin-treated cells. Cells were pretreated with pharmacological inhibitors of p38, JNK, or MEK1 for $30 \mathrm{~min}$ and then further treated with cisplatin for 30 min. Nuclear translocation of NF- $\mathrm{B}$ B was examined by Western blotting. As shown in Figure $8 \mathrm{D}$, pharmacological inhibition of p38 and JNK with SB203580 or SP600125, respectively, did not affect the nuclear translocation of NF- $\kappa$ B in cisplatin-treated cells. However, pretreatment with the MEK1/ERK inhibitors PD98059 and U0126 blocked cisplatin-induced NF-KB activation through the inhibition of $\mathrm{I} \kappa \mathrm{B}$ degradation and consequent translocation of the p65 subunit of NF$\kappa \mathrm{B}$ to the nucleus. We also investigated whether Nrf2 activation was directly involved in the downregulation of cisplatin-mediated MAPK activation. Cisplatin-induced MAPK activation was clearly abolished by wildtype Nrf2 overexpression, but not by DN-Nrf2 (Fig. 8E). Furthermore, DN-Nrf2 overexpression resulted in an attenuation of flunarizine's inhibitory effect on MAPK activations due to cisplatin (Fig. 8E). 
Orally administrated Sibelium decreases the secretion and expression of pro-inflammatory cytokines in vivo

We next examined whether Sibelium (the trade name of flunarizine) modulates the secretion and expression of cisplatin-induced pro-inflammatory cytokines in vivo. Mice were given intraperitoneal injections of

A)

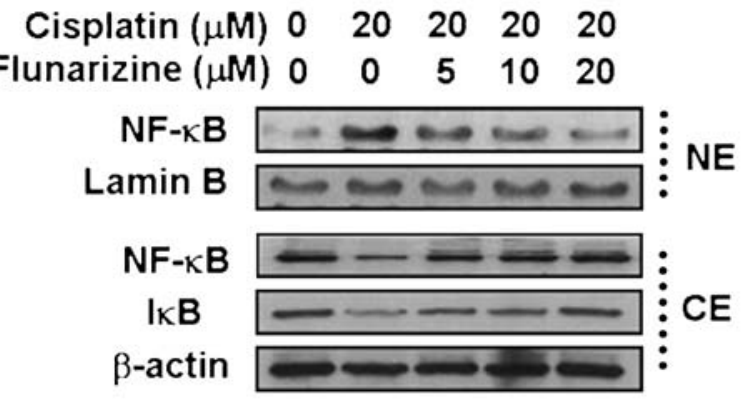

B)

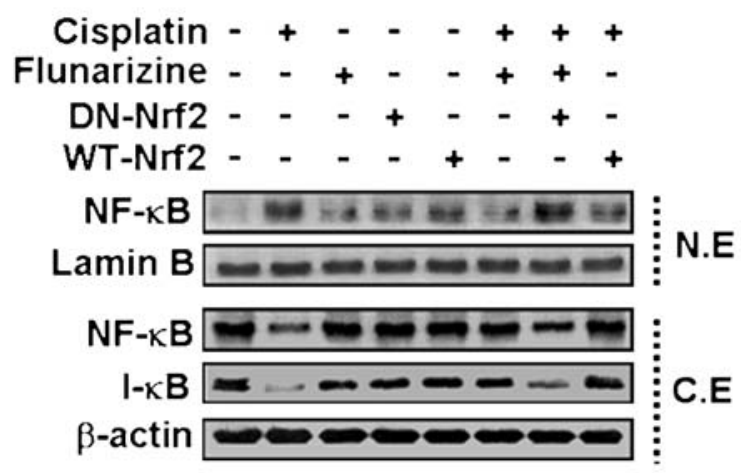

C)

$\begin{array}{cccccc}\text { Cisplatin }(\mu \mathrm{M}) & 0 & 20 & 20 & 20 & 20 \\ \text { Flunarizine }(\mu \mathrm{M}) & 0 & 0 & 5 & 10 & 20 \\ \text { phospho-p38 } & & & \\ \text { p38 } & & & \\ \text { phospho-ERK } & & \\ \text { ERK } & & \\ \text { phospho-JNK } & & \\ \text { JNK1 } & & \end{array}$

FIG. 8. Effect of flunarizine on the nuclear translocation of NF-kB in cisplatin-treated HEI-OC1 cells. A Cells were treated with $20 \mu \mathrm{M}$ cisplatin in the presence of various doses of flunarizine for $1 \mathrm{~h}$. Cytosolic and nuclear fractions were prepared as described in "Methods". These fractions were subjected to 12\% SDS-PAGE and immunoblotted with antibodies specific for NF-kB p65, IкB, VDAC, and $\beta$-actin. B Cells were transfected with Nrf2 expression vectors as described in "Methods". After $48 \mathrm{~h}$, cells were further incubated with $20 \mu \mathrm{M}$ cisplatin for $1 \mathrm{~h}$. Cytosolic and nuclear fractions were immunoblotted with antibodies specific for NF-кB p65, ІкB, VDAC, and $\beta$-actin. C Cells were treated with $20 \mu \mathrm{M}$ cisplatin and various cisplatin for four consecutive days $(4 \mathrm{mg} / \mathrm{kg}$ body weight per injection) with orally administrated Sibelium $(0.143 \mu \mathrm{g} / \mathrm{kg}$ body weight per injection $)$, and the serum levels of three pro-inflammatory cytokines were measured. As shown in Figure 9A-C, serum levels of TNF- $\alpha$, IL-1 $\beta$, and IL- 6 were significantly increased in cisplatin-injected mice compared to PBS-control mice (three to ninefold). Interestingly, orally administrated

D)

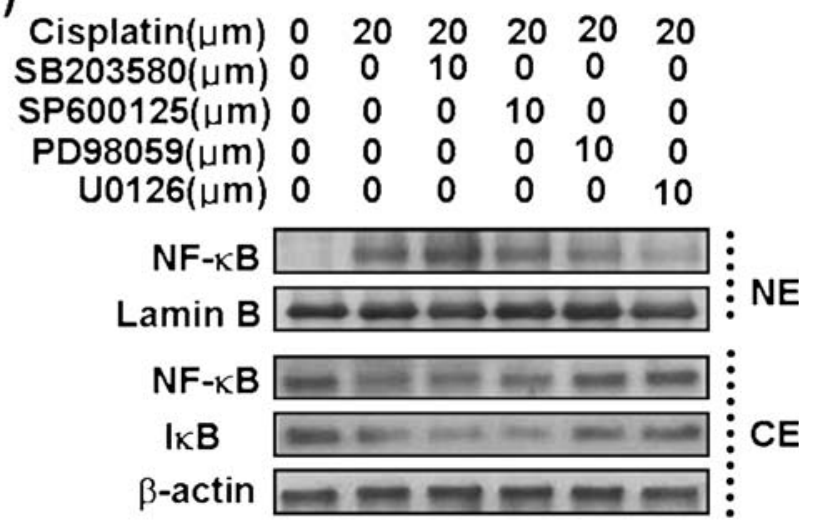

E)

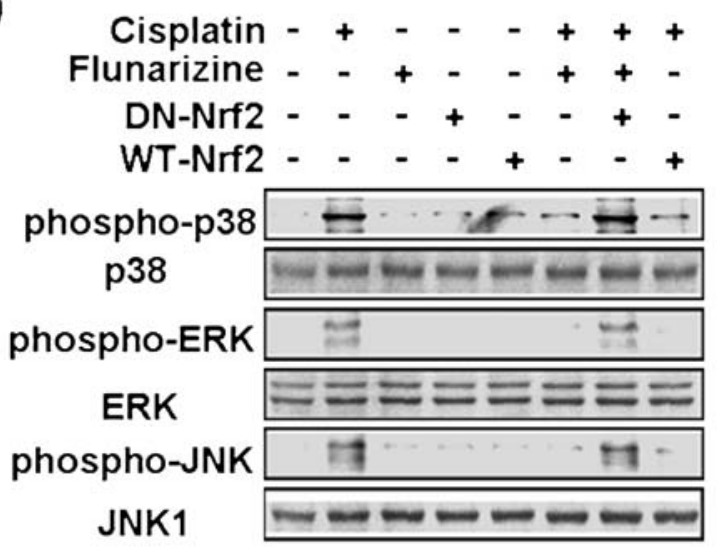

doses of flunarizine for $30 \mathrm{~min}$ and subjected to Western blotting with anti-phospho-MAPK and anti-MAPK antibodies. D Cells were pretreated with pharmacological inhibitors of MAPKs for $30 \mathrm{~min}$ and then further treated with cisplatin for $30 \mathrm{~min}$. Cytosolic and nuclear fractions were immunoblotted with antibodies specific for NF-kB p65, IкB, VDAC, and $\beta$-actin. E Cells were transfected with Nrf2 expression vectors as described in "Methods". After $48 \mathrm{~h}$, cells were further incubated with $20 \mu \mathrm{M}$ cisplatin for $30 \mathrm{~min}$ and subjected to Western blotting with anti-phospho-MAPK and anti-MAPK antibodies. 
Sibelium significantly decreased the serum levels of IL-1 $\beta$ and IL- 6 as well as TNF- $\alpha$. In addition, we examined pro-inflammatory cytokine mRNA levels in whole cochleas of each experimental group using RTPCR. Consistent with the levels of secreted protein, the mRNA levels of TNF- $\alpha$, IL-1 $\beta$, and IL-6 were markedly increased after cisplatin injection compared to PBS-control mice (Fig. 9D). However, simultaneous injection of Sibelium and cisplatin not only completely blocked the expression of TNF- $\alpha$ mRNA but also markedly decreased the expression of IL-1 $\beta$ and IL-6. In HEI-OC1 cells, flunarizine induced HO-1 expres-
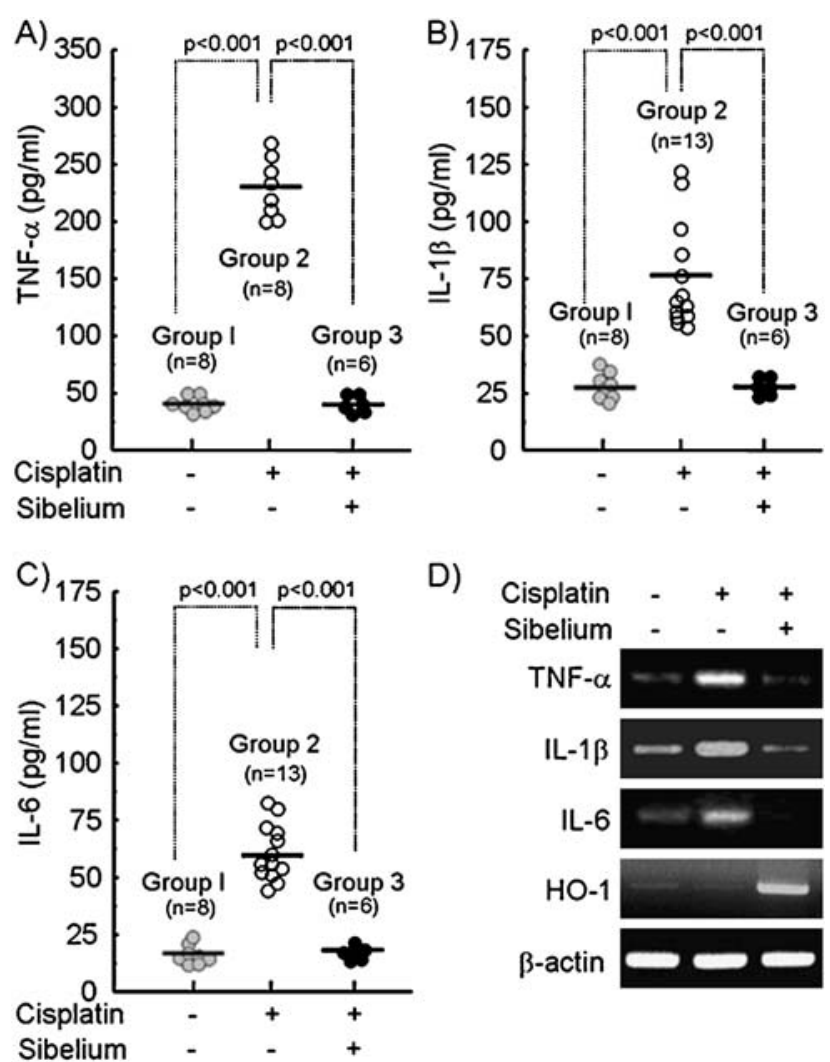

D)

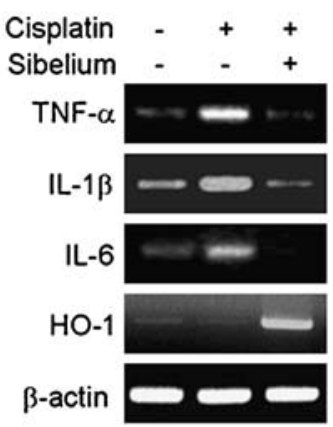

FIG. 9. Effect of Sibelium ${ }^{\mathrm{TM}}$ on cytokine secretion in cisplatintreated Balb/c mice. The animals were randomly divided into three groups (group 1, control; group 2, cisplatin-treated; group 3, cisplatin plus Sibelium-treated). Group 1 received intraperitoneal injections of PBS for four consecutive days. Group 2 received intraperitoneal injections of cisplatin only ( $4 \mathrm{mg} / \mathrm{kg}$, body weight) for four consecutive days. Group 3 received Sibelium (orally administrated, $150 \mu \mathrm{g} / \mathrm{kg}$, body weight) $6 \mathrm{~h}$ before and simultaneous with cisplatin injection ( $4 \mathrm{mg} / \mathrm{kg}$ i.p.) for four consecutive days. The animals in all groups were killed under anesthesia on the day after the final cisplatin injection. Before killing, blood samples were collected into commercial tubes containing EDTA. Pro-inflammatory cytokines from culture supernatants were measured by ELISA. The data represent the mean $\pm \mathrm{SD}$. A Release of TNF- $\alpha$; B Release of IL-1 $\beta$; C Release of IL-6. D Total RNA was then isolated from whole cochleas and cDNA was synthesized by reverse transcriptase. TNF- $\alpha$, IL-1 $\beta$, IL-6, HO- 1 , and $\beta$-actin cDNA sequences were amplified using specific rat primer sets. sion through the Nrf2-driven transcriptional activation of ARE-dependent genes, which plays a critically important role for cellular protection from cisplatin (So et al. 2006). Therefore, we examined HO-1 mRNA expression in the cochleae of Sibelium/ cisplatin-treated mice. As shown in Figure 9D, mRNA levels of HO-1 increased in the cochlea of Sibelium/ cisplatin-treated mice. To investigate the effect of Sibelium on the expression profiles of pro-inflammatory cytokines and HO-1 in the cochlea after cisplatin injection, immunohistochemistry was performed on mice injected with cisplatin only or cisplatin plus Sibelium. Expression of TNF- $\alpha$ was broadly observed throughout the stria vascularis, spiral ligament, spiral ganglion neuron as well as hair cell layers in the organ of Corti from cisplatin-injected mice (Fig. 10B). IL-1 $\beta$ was also widely expressed in stria vascularis, spiral ligament, spiral ganglion neuron as well as hair cell layers in the organ of Corti from cisplatin-injected mice (Fig. 10E). Interestingly, TNF- $\alpha$ and IL-1 $\beta$ expression was co-localized within these regions. On the other hand, very slight expression of IL-6 was detected only in the spiral modular veins and lacunae (data not shown). In both PBS-control mice and Sibelium/cisplatin-coinjected mice, expression of all three pro-inflammatory cytokines was barely detectable (Fig. 10C, F and I).

Activation of the transcription factor NF- $\kappa \mathrm{B}$ is one of the most important mechanisms regulating the expression of pro-inflammatory cytokines (Barnes and Karin 1997). In a previous study, we demonstrated that NF-kB p65 staining was increased in the spiral ligament, stria vascularis, spiral limbus, and the three OHC layers of the organ of Corti in cisplatin-injected rats (So et al. 2007). Therefore, we next examined the expression profile of NF- $\mathrm{KB}$ in the three experimental groups by immunohistochemistry. NF- $\mathrm{B}$ p 65 staining was increased in the spiral ligament, stria vascularis, spiral ganglion neurons, and the three $\mathrm{OHC}$ layers of the organ of Corti in cisplatin-injected mice compared with those of PBS-control or Sibelium/cisplatinco-injected mice (Fig. 11A-C). We also examined whether Sibelium induced the expression of HO-1 in vivo. HO-1 expression was barely detectable in control mice (Fig. 11D), whereas it was slightly detectable in the surrounding regions of inner ear except the spiral ligament, stria vascularis, spiral limbus, and the organ of Corti in cisplatin-injected mice (Fig. 11E). In Sibelium-treated mice, however, HO-1 expression was clearly observed in the spiral ligament, stria vascularis, spiral limbus, and spiral ganglion neurons as well as hair cell layers of the organ of Corti (Fig. 11E). We also examined the cochlea for apoptotic cells as determined by TUNEL staining. In cochleas from PBS-control or Sibelium/cisplatin-coinjected mice, no TUNEL-positive cells were observed (Fig. 11F and G). However, histological sections from 


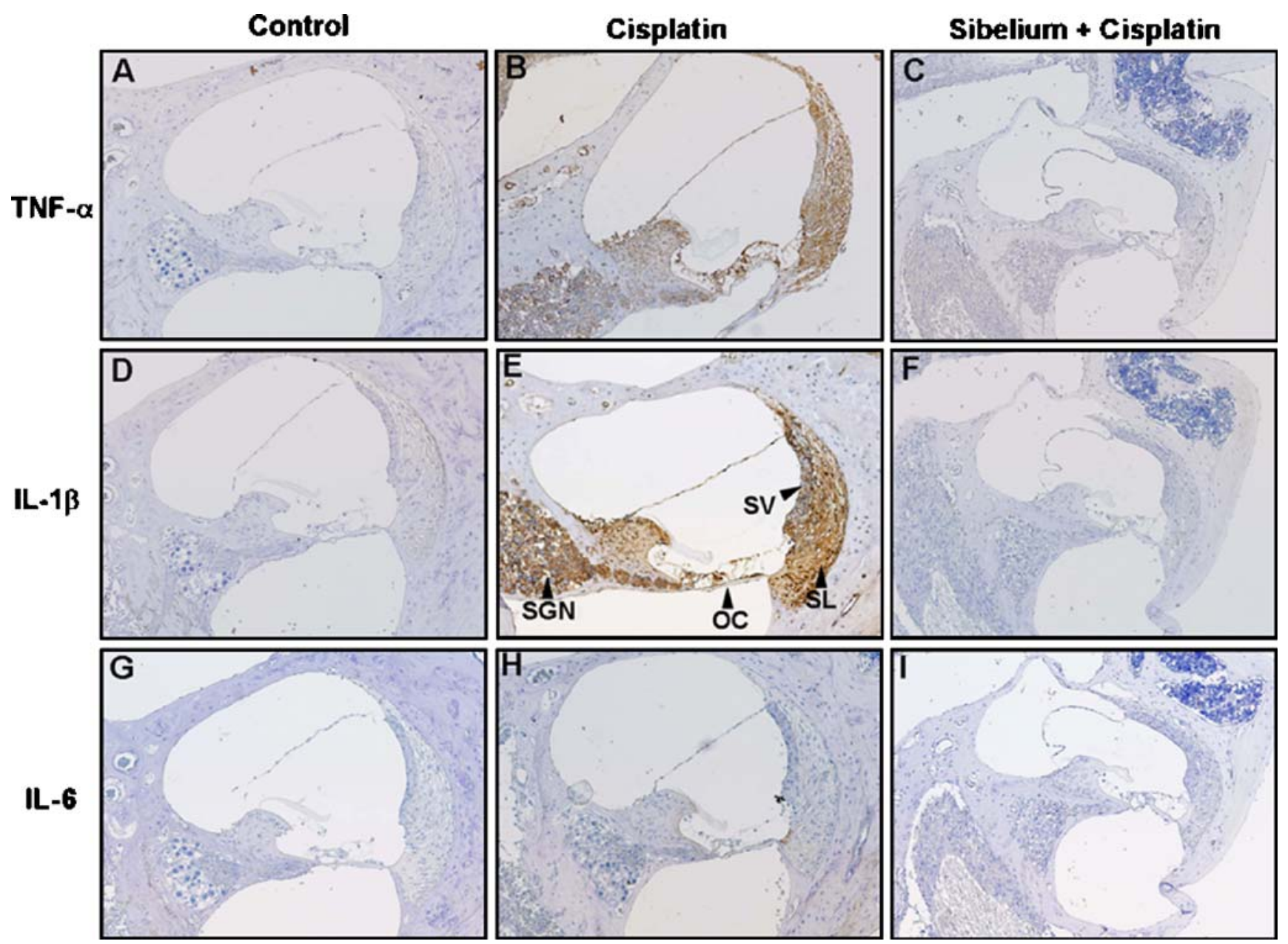

FIG. 10. In vivo effect of Sibelium ${ }^{\mathrm{TM}}$ on cisplatin-induced proinflammatory cytokine expression in the cochlea. Cochleas from Balb/c mice injected with PBS, cisplatin, or cisplatin plus Sibelum ${ }^{\mathrm{TM}}$ were removed and embedded in paraffin, then $5-\mu \mathrm{m}$ sections were prepared. For immunohistochemistry studies, an immunohistochemistry kit (DAKO LSAB Universal K680, Carpinteria, CA, USA) was used, and all the procedures were carried out according to the manufacturer's instructions. The following primary antibodies were

the cisplatin-only-treated mice exhibited many TUNEL-positive cells in the stria vascularis and less so in the spiral ligament, spiral limbus, and the organ of Corti (Fig. 11H).

\section{DISCUSSION}

Accumulating evidence indicates that cochlear and vestibular functions, including hearing and balance, are influenced by immune responses in the inner ear (Rahman et al. 2001). Although immune function in the inner ear is very important in the protection from infectious diseases such as labyrinthitis, immunerelated inflammatory responses also cause damage to the delicate tissues of inner ear compartments and employed: anti-TNF- $\alpha$ (goat polyclonal anti-mouse TNF- $\alpha, R \& D$ Systems); anti-IL-1 $\beta$ (goat polyclonal anti-mouse IL-1 $\beta$, R\&D Systems); anti-IL-6 (goat polyclonal anti-mouse IL-6, R\&D Systems); antiNF-кB p65 (rabbit polyclonal IgG, Santa Cruz). This figure is representative of three individual animals from each group. $S L$ spiral ligament, $S V$ stria vascularis, $S G N$ spiral ganglion neuron, $O C$ organ of Corti.

can often lead to cochlear degeneration and permanent hearing loss (Ryan et al. 2002; Satoh et al. 2003). Of note, cisplatin also caused ototoxicity through the apoptotic death of OHCs and supporting cells in the organ of Corti accompanying the secretion and expression of the pro-inflammatory cytokines TNF- $\alpha$, IL-1 $\beta$, and IL-6 (So et al. 2007).

A cis-acting regulatory ARE is located in the promoter regions of several genes encoding phase II detoxification enzymes and antioxidant proteins such as $\mathrm{NAD}(\mathrm{P}) \mathrm{H}$ :quinine oxidoreductase-1 (NQO1), glutathione S-transferase (GST), $\gamma$-glutamylcysteine synthetase ( $\gamma$-GCS), heme oxygenase 1 (HO-1), thioredoxin reductase-1, and thioredoxin (Jaiswal 2004). These genes are mainly upregulated by the transcriptional activation of Nrf2 through the direct 


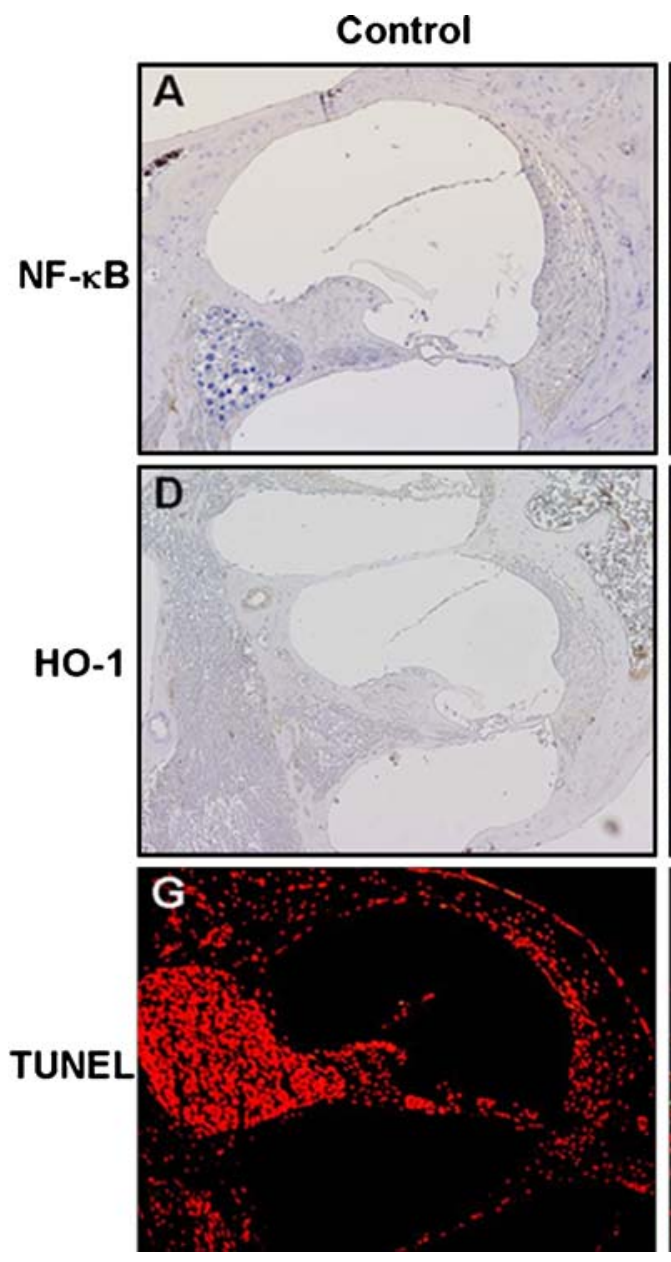

FIG. 11. In vivo effect of Sibelium ${ }^{\mathrm{TM}}$ on $\mathrm{HO}^{-1}$ expression and cisplatin-induced NF- $\mathrm{\kappa B}$ expression in the cochlea. Five-micrometer cochlear sections from each experimental group were stained with anti-NF-KB (A-C), anti-HO-1 (D-F) and TUNEL (G-I). This figure is

\section{Cisplatin}
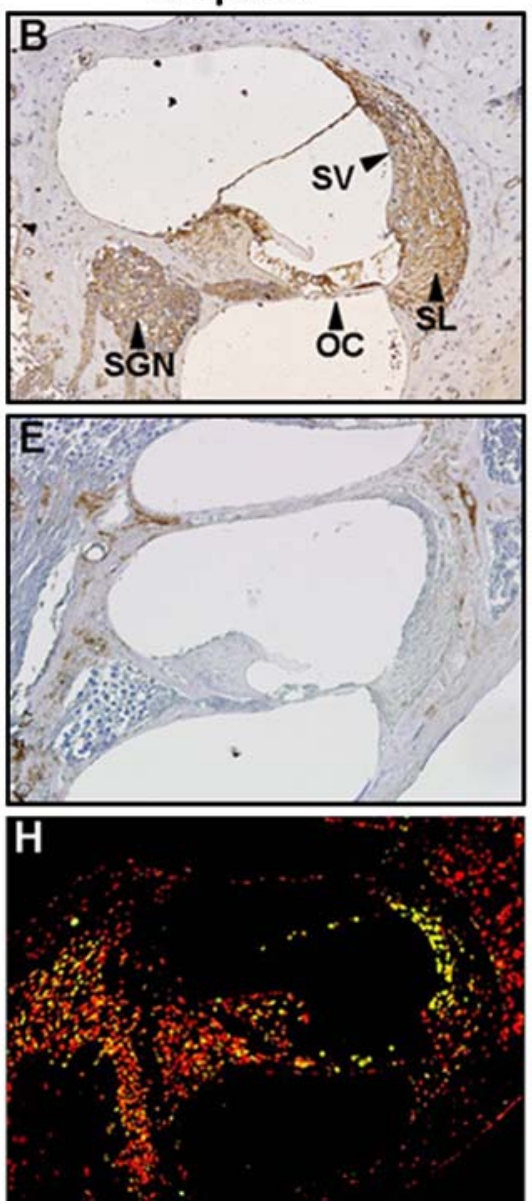

Sibelium + Cisplatin
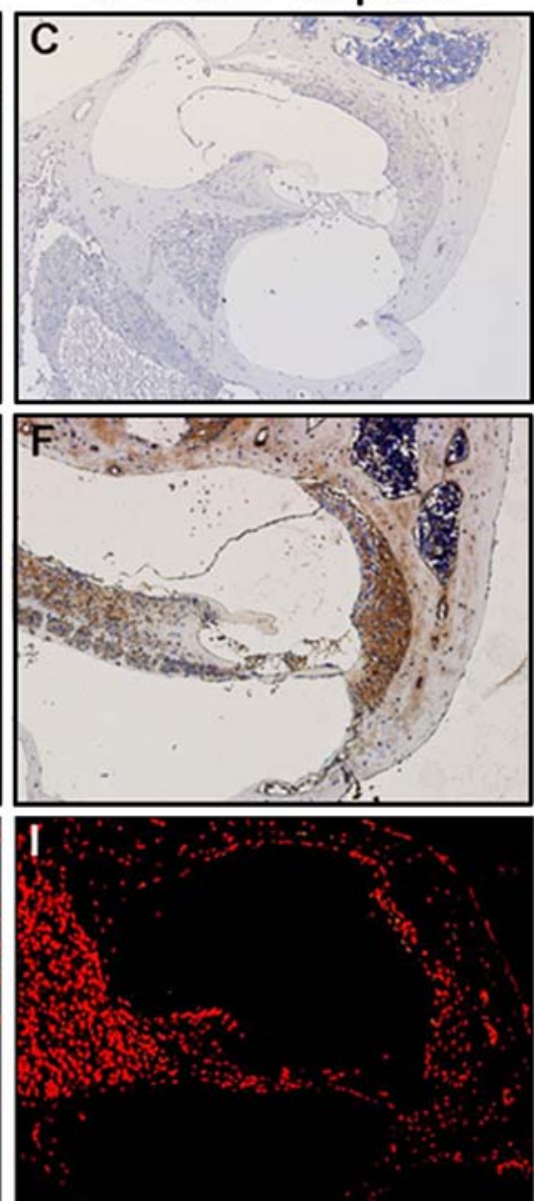

representative of three individual animals from each group. $S L$ spiral ligament, SV stria vascularis, SGN spiral ganglion neuron, OC organ of Corti.

binding to ARE. Nrf2 is abundantly expressed in liver, intestine, lung, and kidney where detoxification reactions occur routinely. Recently, it has been shown that Nrf2 and its downstream effectors act as critically important regulators in the protection of cells from oxidative stress and chemical-induced damage of liver and lung tissues by the regulation of intracellular redox status (Chan and Kan 1999; Chan et al. 2001). It was demonstrated that Nrf2 knockout mice are more sensitive to hyperoxic injury of lung tissue (Cho et al. 2002) and Nrf2 deficiency results in early embryonic lethality with severe oxidative stress (Leung et al. 2003). In addition to its role in regulating ROS levels, several recent studies have showed that the Nrf2 pathway regulates immune and inflammatory processes. Yoh et al. (2001) reported that Nrf2-deficient female mice developed lupus-like autoimmune nephritis. It was also demonstrated that Nrf2-deficient mice exhibit prolonged inflammation during cutaneous wound healing and display en- hanced bronchial inflammation and susceptibility to cigarette smoke-induced emphysema (Iizuka et al. 2005). These data suggest that Nrf2 deficiency and the resulting impaired antioxidant activity are important in the determination of susceptibility to autoimmune and inflammatory diseases. In this study, we showed that flunarizine significantly increases the cell viability of cisplatin-treated HEI-OC1 cells and inhibits pro-inflammatory cytokine secretion and mRNA transcription due to cisplatin (Figs. 1 and 2). Of note, the overexpression of wild-type Nrf2 apparently attenuates cisplatin-induced pro-inflammatory cytokine secretion, whereas dominant negative Nrf2 does not. Knock down of Nrf2 expression by Nrf2-specific siRNA resulted in the attenuation of flunarizine's effect on pro-inflammatory cytokine secretion (Fig. 6). These data indicate that the activation of Nrf2 signaling is critical for the attenuating effect of flunarizine on cisplatin-induced pro-inflammatory cytokine secretion. 


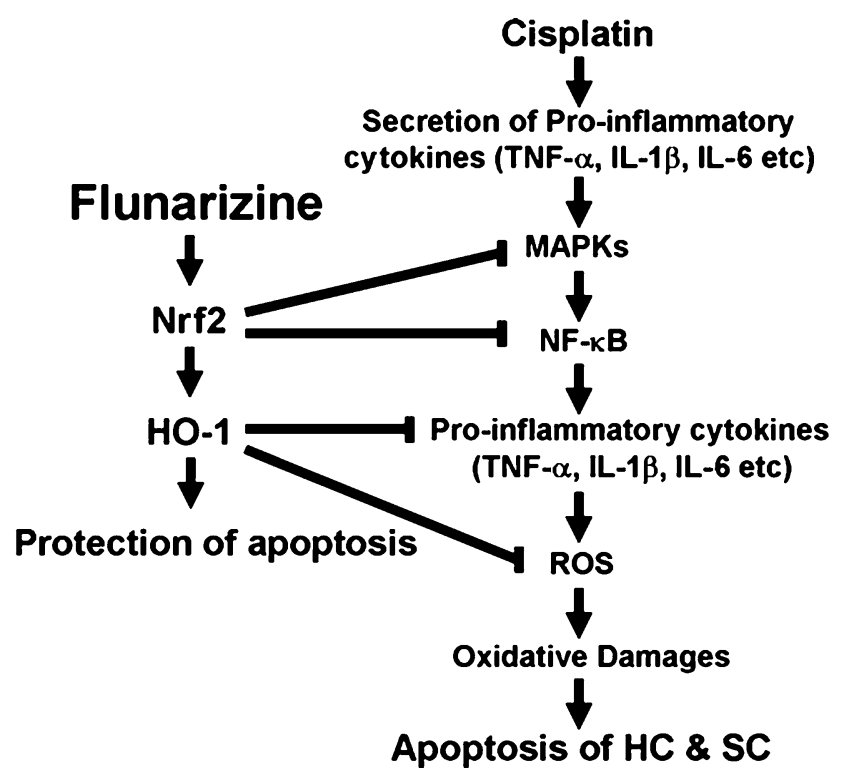

FIG. 12. Protective mechanisms of flunarizine via $\mathrm{Nrf} / \mathrm{HO}-1$ activation against cisplatin-induced auditory cell damages. The scheme shows that flunarizine attenuated cisplatin-induced proinflammatory cytokine production and thereby induced a cytoprotective effect against cisplatin cytotoxicity. Cisplatin induced MAPK and NF- $\mathrm{KB}$ activations which promoted the expression of proinflammatory genes including TNF- $\alpha$, IL- $1 \beta$, and IL-6. However, flunarizine inhibited the cisplatin-induced MAPKs and NF-KB via the activation of Nrf2/HO-1 signaling pathway. HC hair cells, SC supporting cells

Heme oxygenase (HO), one of the Nrf-2 downstream target enzymes, degrades heme into biliverdin, $\mathrm{CO}$, and free iron $\left(\mathrm{Fe}^{2+}\right)$. Biliverdin is rapidly reduced to bilirubin by biliverdin reductase, whereas free iron released from the heme molecule is used in intracellular metabolism as well as being sequestered by the iron chelator, ferritin. HO-1 is expressed at very low levels in the outer hair cells of normal rat cochleas (Fairfield et al. 2004). It has also shown the critical importance of HO-1 expression in mediating antioxidant, anti-inflammatory, and anti-apoptotic effects (Jaiswal 2004). In our study, pharmacological induction of HO-1 significantly attenuated cisplatin-induced pro-inflammatory cytokine secretion, whereas pharmacological suppression of HO-1 activity by the HO-1 inhibitor ZnPPIX or transfection of HO-1 siRNA markedly abolished the attenuating effect of flunarizine on cisplatin-induced pro-inflammatory cytokine secretion. Furthermore, HO-1 expression in vivo was widely observed in the spiral ligament, stria vascularis, spiral limbus, and spiral ganglion neurons as well as hair cell layers of the organ of Corti in Sibelium ${ }^{\text {TM }}$ treated mice (Fig. 11E). Interestingly, in the stria vascularis, HO-1 expression was markedly increased in the marginal and intermediate cells, but not in the basal cells (data not shown), which is consistent with a report that after hyperthermia, the level of HO-1 protein is markedly induced, with selective localization among all three rows of outer hair cells in the organ of Corti and in the marginal and intermediate cells of the stria vascularis (Fairfield et al. 2004).

Although the beneficial mechanisms of HO-1 induction have not been fully elucidated, several have been suggested. Increased HO-1 activity results in the generation of bilirubin by enzymatic degradation of the heme moiety, a potentially toxic pro-oxidant. This bilirubin acts as an antioxidant capable of scavenging peroxy radicals and inhibiting lipid peroxidation. It has been demonstrated that exogenous treatment with bilirubin provides in vitro protection against oxidative stress and hypoxia in mammalian cell culture and in vivo protection against ischemia in the rat heart (Clark et al. 2000) and intestine (Ceran et al. 2001). In addition, CO, another product of heme catabolism, showed a number of cytoprotective functions during various conditions of oxidative stress, including hyperoxic lung injury, endotoxemia, and graft rejection of the liver, heart, and lung (Otterbein and Choi 2000). CO inhibits apoptosis in various cells, including fibroblasts, endothelial cells, and vascular smooth muscle cells (Liu et al. 2002). Liu et al. (2002) also reported that the survival of cultured vascular cells is mediated by the production of $\mathrm{CO}$, as cytoprotection obtained from HO-1 is reversed by a CO scavenger, hemoglobin. Regarding how CO exerts its potent protective effects, several mechanisms have been suggested. CO showed functions as a potent vasodilator, a putative neurotransmitter, and an anti-inflammatory agent which inhibits both platelet aggregation and activation through the activation of the soluble guanylate cyclase (sGC)/cyclic guanosine monophosphate (cGMP) pathway (Otterbein and Choi 2000). CO also suppresses the expression of certain pro-inflammatory cytokines (e.g., TNF- $\alpha$, IL-1 $\beta$ ) and chemokines (Soares et al. 2004) and upregulates the expression of the anti-inflammatory cytokine IL-10 (Otterbein et al. 2000). Similar to these previous studies, we also demonstrated that $\mathrm{CO}$ and bilirubin, catabolic metabolites of HO-1, play a critical role in the attenuation of pro-inflammatory cytokine production due to cisplatin (Table 1). Furthermore, addition of the CO scavenger, hemoglobin, slightly but significantly inhibited the attenuating effect of flunarizine on TNF- $\alpha$ and IL-1 $\beta$ secretion (Fig. 7 ), indicating that the protective effect of flunarizine against cisplatin cytotoxicity in HEI-OC1 cells is accomplished, at least in part, in a CO-dependent manner.

The expression of pro-inflammatory cytokines and other pro-inflammatory mediators that participate in acute inflammatory responses are widely regulated by the NF- $\kappa$ B transcription factor (Abraham 2003). The most abundant form of NF-KB is a heterodimer of p50 
and p65 subunits, which, in resting cells, is sequestered in the cytoplasm as an inactive complex bound

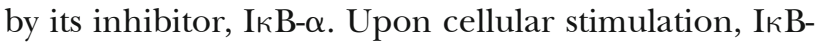
$\alpha$ protein is phosphorylated and targeted for ubiquitination and subsequent degradation by the $26 \mathrm{~S}$ proteosome (Chang and Karin 2001). NF- $\kappa$ B subsequently is released and translocated to the nucleus to activate the expression of various target genes (Suzuki et al. 2000; Wang et al. 2003). Pro-inflammatory cytokines such as TNF- $\alpha$ and IL-1 $\beta$ can also activate $\mathrm{NF}-\kappa \mathrm{B}$ through signal transduction involving the TNF receptor associated factor (TRAF) family of adaptor proteins (Dempsey et al. 2003). TNF- $\alpha$ receptors phosphorylate $\mathrm{I} \kappa \mathrm{B}$ kinase, which in turn leads to $\mathrm{I} \kappa \mathrm{B}$ degradation in proteosomes and the intranuclear translocation of NF- $\kappa \mathrm{B}$ subunits. NF- $\kappa \mathrm{B}$ activation regulates a plethora of genes including pro-inflammatory cytokines such as TNF- $\alpha$, IL-1 $\beta$, and IL-6 (Baldwin 1996; Barnes and Karin 1997).

Interestingly, NF- $\mathrm{B}$ has a dual function as apoptotic or anti-apoptotic effector. It suppresses apoptosis by inducing the expression of multiple anti-apoptotic proteins such as inhibitor of apoptosis proteins (IAPs), X-linked IAP, cellular Fas-associated death domain-like IL-1 $\beta$-converting enzyme (FLICE) inhibitory protein (cFLIP), and Bcl-XL (Kucharczak et al. 2003). However, other lines of reports also support that NF- $\mathrm{B}$ induces apoptosis. NF- $\kappa \mathrm{B}$ contributes to apoptosis by upregulating its pro-apoptotic target genes such as Fas/CD95, FasL, death receptor 4 (DR4/TRAIL-R1), and DR5 (TRAIL-R2) while repressing anti-apoptotic target genes. The essential of NF$\kappa \mathrm{B}$ on either induction of apoptosis or inhibition of apoptosis is mainly dependent on the variety of stimuli, cell-types, and the subunit types involved (Lee et al. 2007).

In this study, we have shown that flunarizine blocks the nuclear translocation of NF- $\mathrm{B}$ accompanying the inhibition of cytoplasmic NF- $\kappa \mathrm{B}$ decrease and I $\kappa \mathrm{B}-\alpha$ degradation after cisplatin exposure (Fig. 8A). Furthermore, we observed the increase of cisplatin-mediated NF- $\mathrm{B}$ p 65 expression in the spiral ligament, stria vascularis, and spiral limbus, but these expressions were clearly blocked by flunarizine (Fig. 11B and C).

We also demonstrated that flunarizine attenuates cisplatin-mediated MAPK activation (Fig. 8C and D). Therefore, it was of interest how flunarizine modulates the link between NF- $\kappa \mathrm{B}$ activation and MAPK activation for pro-inflammatory cytokine production in cisplatin-treated cells. First, we investigated the possibility of direct cross talk between NF- $\kappa \mathrm{B}$ and Nrf2 activated by flunarizine in HEI-OC1 cells. We showed that WT-Nrf2 overexpression abolishes both cytosolic I $\kappa \mathrm{B}-\alpha$ degradation and nuclear translocation of NF- $\kappa \mathrm{B}$ after cisplatin exposure. These results suggest the possibility of cross talk between Nrf2 and NF-kB signaling event. It has been known that MAPKs regulate many cellular events, including differentiation, proliferation, and apoptosis (Lewis et al. 1998).

Signaling cascades through ERK activation can be anti-apoptotic or apoptotic depending on cell types and the nature of stimuli. Anti-apoptotic effects of ERK activation against a diverse range of apoptotic signals, including serum-deprivation-induced apoptosis of PC12 cells (Yan and Greene 1998) and TNF- $\alpha-$ induced apoptosis of L929 cells (Gardner and Johnson 1996), have been reported. Apoptosis signaling through ERK activation have also been described (Zhuang and Schnellmann 2006). In a mouse model of cisplatin-induced nephrotoxicity, ERK activation was observed in distal tubules and collecting ducts of kidney after cisplatin administration. Inhibition of ERK activation by MEK inhibitor reduced tissue damage and improved renal function (Jo et al. 2005).

In addition, recently, a number of in vitro studies have shown that the production of inflammatory mediators is strongly affected by MAPKs. For example, it has been reported that the p38 and ERK pathways play an important role in IL-1 $\beta$ and TNF- $\alpha$ production, respectively (Hsu and Wen 2002; Shi et al. 2002). Therefore, we speculated that modulation of other signaling events involving MAPKs by flunarizine might affect the activation of NF- $\kappa \mathrm{B}$ by cisplatin and consequently attenuate pro-inflammatory cytokine production and apoptotic cell death after cisplatin exposure. This speculation is supported by our results showing that the MAPKs ERK, JNK, and p38 are activated by cisplatin, whereas the inhibition of MEK1/ERK markedly decreased the cytotoxicity of cisplatin as well as the expression levels of TNF- $\alpha$, IL$1 \beta$, and IL-6 mRNAs in cisplatin-treated cells. In addition, pharmacological inhibition of MEK1/ERK markedly blocked cisplatin-induced NF- $\kappa \mathrm{B}$ activation through the downregulation of $\mathrm{I} \kappa \mathrm{B}$ degradation and translocation of the p65 subunit of NF- $\mathrm{B}$ to the nucleus. Furthermore, WT-Nrf2 overexpression effectively blocked MAPK activation after cisplatin exposure (Fig. 8E). These results suggest that MAPK signaling events mediate the link between Nrf2 and NF- $\mathrm{B}$. Based on the results presented here, the mechanisms by which flunarizine inhibits cisplatin-induced auditory cell damage are summarized in Figure 12.

Taken together, our present results suggest that flunarizine induces protection against cisplatin cytotoxicity through the downregulation of MAPKs and NF- $\mathrm{B}$ signaling by Nrf2 activation and, thereby, the inhibition of pro-inflammatory cytokine production. In addition, Nrf2/HO-1 activation or anti-inflammatory agents may provide new opportunities for pharmacotherapy with regard to cisplatin and immune-mediated disorders of hearing and balance. 


\section{ACKNOWLEDGMENTS}

This work was supported by the Ministry of Science \& Technology (MoST)/Korea Science \& Engineering Foundation (KOSEF) through the Vestibulocochlear Research Center (VCRC) at Wonkwang University in 2007 (R13-2002055-03001-0). HongSeob So and HyungJin Kim contributed equally to this work.

\section{REFERENCES}

Авяднам E. Nuclear factor-kappaB and its role in sepsis-associated organ failure. J. Infect. Dis. 187(Suppl 2):S364-S369, 2003.

Akamatsu Y, Haga M, Tyagi S, Yamashita K, Graca-souza AV, Ollinger R, Czismadia E, May GA, Ifedigbo E, Otterbein LE, Bach FH, SOARES MP. Heme oxygenase-1-derived carbon monoxide protects hearts from transplant associated ischemia reperfusion injury. FASEB J. 18:771-772, 2004.

BALDWIN AS, JR. The NF-kappa B and I kappa B proteins: new discoveries and insights. Annu. Rev. Immunol. 14:649-683, 1996.

Barnes PJ, Karin M. Nuclear factor-kappaB: a pivotal transcription factor in chronic inflammatory diseases. N. Engl. J. Med. 336:1066-1071, 1997.

Ceran C, Sonmez K, Turkyllmaz Z, Demirogullarl B, Dursun A, Duzgun E, Basakiar AC, Kale N. Effect of bilirubin in ischemia/ reperfusion injury on rat small intestine. J. Pediatr. Surg. 36:1764-1767, 2001.

Chan K, Kan YW. Nrf2 is essential for protection against acute pulmonary injury in mice. Proc. Natl. Acad. Sci. U. S. A. 96:12731-12736, 1999.

Chan K, Han XD, Kan YW. An important function of Nrf2 in combating oxidative stress: detoxification of acetaminophen. Proc. Natl. Acad. Sci. U. S. A. 98:4611-4616, 2001.

Chang L, KARIN M. Mammalian MAP kinase signalling cascades. Nature 410:37-40, 2001.

Cho HY, Jedlicka AE, Reddy SP, Kensler TW, Yamamoto M, Zhang LY, KLEEBERGER SR. Role of NRF2 in protection against hyperoxic lung injury in mice. Am. J. Respir. Cell. Mol. Biol. 26:175-182, 2002.

Clark Je, Foresti R, Sarathchandra P, Kaur H, Green CJ, Motterlini R. Heme oxygenase-1-derived bilirubin ameliorates postischemic myocardial dysfunction. Am. J. Physiol. Heart. Circ. Physiol. 278: H643-651, 2000.

Dempsey PW, Doyle SE, He JQ, Cheng G. The signaling adaptors and pathways activated by TNF superfamily. Cytokine Growth Factor Rev. 14:193-209, 2003.

Fairfield DA, Kanicki AC, Lomax MI, Altschuler RA. Induction of heat shock protein 32 (Hsp32) in the rat cochlea following hyperthermia. Hear. Res. 188:1-11, 2004.

FrAM RJ. Cisplatin and platinum analogues: recent advances. Curr. Opin. Oncol. 4:1073-1079, 1992.

GARDNER AM, Johnson GL. Fibroblast growth factor-2 suppression of tumor necrosis factor alpha-mediated apoptosis requires Ras and the activation of mitogen-activated protein kinase. J. Biol. Chem. 271:14560-14566, 1996.

Hsu HY, WEN MH. Lipopolysaccharide-mediated reactive oxygen species and signal transduction in the regulation of interleukin-1 gene expression. J. Biol. Chem. 277:22131-22139, 2002.

Iizuka T, Ishi Y, Itoh K, Kiwamoto T, Kimura T, Matsuno Y, Morishima Y, Hegab AE, Homma S, Nomura A, Sakamoto T, Shimura M, Yoshida A, Yamamoto M, Sekizawa K. Nrf2-deficient mice are highly susceptible to cigarette smoke-induced emphysema. Genes Cells 10:1113-1125, 2005.
JAISWAL AK. Nrf2 signaling in coordinated activation of antioxidant gene expression. Free Radic. Biol. Med. 36:1199-1207, 2004.

Jo SK, Cho WY, Sung SA, Kim HK, Won NH. MEK inhibitor, U0126, attenuates cisplatin-induced renal injury by decreasing inflammation and apoptosis. Kidney Int. 67:458-466, 2005.

Kalinec GM, Webster P, Lim DJ, Kalinec F. A cochlear cell line as an in vitro system for drug ototoxicity screening. Audiol. Neurootol. 8:177-189, 2003.

Kanzaki J, Ouchi T. Steroid-responsive bilateral sensorineural hearing loss and immune complexes. Arch. Oto-rhino-laryngol. 230:5-9, 1981.

Kim HJ, So HS, Lee JH, Park C, Park SY, Kim YH, Youn MJ, Kim SJ, Chung SY, Lee KM, PARK R. Heme oxygenase-1 attenuates the cisplatin-induced apoptosis of auditory cells via down-regulation of reactive oxygen species generation. Free Radic. Biol. Med. 40:1810-1819, 2006.

Kucharczak J, Simmons MJ, Fan Y, Gelinas C. To be, or not to be: NFkappaB is the answer-role of Rel/NF-kappaB in the regulation of apoptosis. Oncogene 22:8961-8982, 2003.

LEe CH, JeON YT, KIM SH, SONG YS. NF-kappaB as a potential molecular target for cancer therapy. Biofactors 29:19-35, 2007.

Leung L, Kwong M, Hou S, Lee C, Chan JY. Deficiency of the Nrf1 and Nrf2 transcription factors results in early embryonic lethality and severe oxidative stress. J. Biol. Chem. 278:48021-48029, 2003.

LewIs TS, SHAPIRo PS, AHN NG. Signal transduction through MAP kinase cascades. Adv. Cancer Res. 74:49-139, 1998.

Liu XM, Chapman GB, Wang H, Durante W. Adenovirus-mediated heme oxygenase-1 gene expression stimulates apoptosis in vascular smooth muscle cells. Circulation 105:79-84, 2002.

McAlpine D, Johnstone BM. The ototoxic mechanism of cisplatin. Hear. Res. 47:191-203, 1990.

McCABE BF. Autoimmune sensorineural hearing loss. 1979. Ann. Otol. Rhinol. Laryngol. 113:526-530, 2004.

Otterbein LE, Choi AM. Heme oxygenase: colors of defense against cellular stress. Am J Physiol Lung Cell. Mol. Physiol. 279:L1029L1037, 2000.

Otterbein LE, Bach FH, Alam J, Soares M, Tao Lu H, Wysk M, Davis RJ, Flavell RA, Choi AM. Carbon monoxide has anti-inflammatory effects involving the mitogen-activated protein kinase pathway. Nat. Med. 6:422-428, 2000.

Rahman MU, Poe DS, ChOI HK. Autoimmune vestibulo-cochlear disorders. Curr. Opin. Rheumatol. 13:184-189, 2001.

RyAn AF, Harris JP, KeITHLey EM. Immune-mediated hearing loss: basic mechanisms and options for therapy. Acta Oto-Laryngol Suppl. 548:38-43, 2002.

Rrbak LP, Somani S. Ototoxicity. Amelioration by protective agents. Ann. N. Y. Acad. Sci. 884:143-151, 1999.

Satoh H, Firestein GS, Billings PB, Harris JP, Keithley EM. Proinflammatory cytokine expression in the endolymphatic sac during inner ear inflammation. J. Assoc. Res. Otolaryngol. 4:139-147, 2003.

Shi L, Kishore R, McMullen MR, NAgy LE. Lipopolysaccharide stimulation of ERK1/2 increases TNF-alpha production via Egr1. Am. J. Physiol. Cell Physiol. 282:C1205-C1211, 2002.

So HS, Park C, Kim HJ, Lee JH, Park SY, Lee ZW, Kim HM, Kalinec F, Lim DJ, PARK R. Protective effect of T-type calcium channel blocker flunarizine on cisplatin-induced death of auditory cells. Hear. Res. 204:127-139, 2005.

So HS, Kim HJ, LeE JH, PARK SY, PARK C, Kim YH, Kim JK, LeE KM, Kim KS, Chung SY, Jang WC, Moon SK, Chung HT, Park RK. Flunarizine induces Nrf2-mediated transcriptional activation of heme oxygenase-1 in protection of auditory cells from cisplatin. Cell Death Differ. 13:1763-1775, 2006.

So H, Kim H, Lee JH, Park C, Kim Y, Kim E, Kim JK, Yun KJ, Lee KM, LeE HY, MoOn SK, Lim DJ, PARK R. Cisplatin cytotoxicity of auditory cells requires secretions of proinflammatory cytokines via activation of ERK and NF-kappaB. J. Assoc. Res. Otolaryngol. 8:338-355, 2007. 
Soares MP, Seldon MP, Gregoire IP, Vassilevskaia T, Berberat PO, Yu J, Tsui TY, BACH FH. Heme oxygenase-1 modulates the expression of adhesion molecules associated with endothelial cell activation. J. Immunol. 172:3553-3563, 2004.

Suzuki M, Tetsuka T, Yoshida S, Watanabe N, Kobayashi M, Matsui N, Окамото T. The role of p38 mitogen-activated protein kinase in IL-6 and IL-8 production from the TNF-alpha- or IL-1betastimulated rheumatoid synovial fibroblasts. FEBS Lett. 465:2327, 2000

Wang L, Walia B, Evans J, Gewirtz AT, Merlin D, Sitaraman SV. IL-6 induces NF-kappa B activation in the intestinal epithelia. J. Immunol. 171:3194-3201, 2003.
YAn CY, Greene LA. Prevention of PC12 cell death by N-acetylcysteine requires activation of the Ras pathway. J. Neurosci. 18:4042-4049, 1998.

Yoh K, Itoh K, Enomoto A, Hirayama A, Yamaguchi N, Kobayashi M, Morito N, Koyama A, Yamamoto M, Takahashi S. Nrf2-deficient female mice develop lupus-like autoimmune nephritis. Kidney Int. 60:1343-1353, 2001.

Yoshida K, Ichimira I, Suzuki M, Mogi G. Effect of proinflammatory cytokines on cultured spiral ligament fibrocytes. Hear. Res. 137:155-159, 1999.

Zhuang S, Schnellmann RG. A death-promoting role for extracellular signal-regulated kinase. J. Pharmacol. Exp. Ther. 319:991-997, 2006. 